\title{
Optimization of an isolated photo-voltaic generating unit with battery energy storage system using electric system cascade analysis
}

\author{
Ranjay Singh, R.C. Bansal, Arvind R. Singh
}

aDepartment of Electrical, Electronic and Computer Engineering, University of Pretoria, South Africa.

\begin{abstract}
This paper presents an improvement to the iterative method of Electric System Cascade Analysis (ESCA) for the optimisation of an isolated PV system with Battery Energy Storage System (BESS) for a residential load. The ESCA algorithm is implemented on MATLAB software environment with Final Excess Energy (FEE), Loss of Power Supply Probability (LPSP) and system cost as optimization constraints. The load, temperature and solar radiation profiles are considered for a year, based on historical data. Practical losses in solar radiation reaching the PV collector surface are considered for analysis. Change in PV efficiency due to variation in temperature and change in charge /discharge efficiency of the battery based on current State of Charge (SOC) of BESS are taken into consideration which further bolsters the credibility of the ESCA methodology. The ESCA methodology is used to optimize a PV-BESS system for a residential load with average daily consumption of 26.1 kWh. The optimized result obtained from improved ESCA are compared and verified with benchmark HOMER software.
\end{abstract}

Keywords- PV system, battery storage system, Power Pinch Analysis (PoPA), Electric System Cascade Analysis, HOMER, system optimization.

\section{Introduction}

Attention towards renewable energy generation has increased in the past two decades because of the high increase in energy demand and harmful impacts of the conventional energy generation [1]. Among the renewable sources like solar, wind, bio-power, geothermal, etc., the most popular resources are wind and solar [2]. For small load areas, solar energy presents the best solution because of ease of installation and low maintenance. In 2017, China with $131 \mathrm{GW}$ of installed capacity is the world leader in solar PV generation followed by Japan at 49 GW and USA at 43 GW [3]. The total installed capacity of solar PV of the world in 2017 is $397 \mathrm{GW}$, which is expected to increase to 489 GW by 2020 and 1760 GW by 2030 [3]. Stress on the conventional energy sources can be greatly reduced by penetration of renewable energy sources into the current grid, but the popularity of standalone system with high renewable energy penetration has gained recently, for example, Liu et al. [4] have performed comparative study of various configuration of isolated renewable energy systems. Yilmaz et al. [5] have performed optimization of isolated hybrid renewable energy system for city in Turkey. Fara et al. [6] have designed and modelled an isolated PV system for a mountain village in Romania. Researchers [7]-[9] have shown in their literature review that hybrid renewable energy system has a rising trend in isolated system studies. For isolated systems, it is prudent to use energy storage unit(s) to overcome the uncertainty in power generation from renewable sources like solar and wind [10]. Even though addition of storage provides higher reliability of power, but the cost of the system and control complexity of the system increases [11]. Therefore, optimal sizing of the renewable energy system becomes important. There are several studies which have been conducted using optimization techniques like Particle Swarm Optimization (PSO), Genetic Algorithm (GA), etc. and software like 


\begin{tabular}{|c|c|c|c|}
\hline \multicolumn{4}{|c|}{ Symbols } \\
\hline $\mathrm{E}_{\mathrm{pV}}$ & Hourly energy generated (Wh) & $E_{c}(t)$ & Net accumulated charge in BESS (Wh) \\
\hline $\mathrm{N}_{\mathrm{PV}}$ & Number of PV panels & $P_{\text {inv }}$ & Inverter rating (Watts) \\
\hline$A_{P V}$ & Area of each PV panel $\left(\mathrm{m}^{2}\right)$ & $\mathrm{P}_{\mathrm{L}}(\max )$ & Max load (Watts) \\
\hline $\mathrm{I}(\mathrm{t})$ & Hourly solar radiation $\left(\mathrm{Wh} / \mathrm{m}^{2}\right)$ & $\mathrm{C}_{\mathrm{ICC}}$ & Initial capital cost (\$) \\
\hline$\eta_{\mathrm{pv}}$ & Calculated PV panel efficiency (\%) & $\mathrm{C}_{\mathrm{TSC}}$ & Total cost of the system (\$) \\
\hline$\eta_{\mathrm{r}}$ & Rated PV panel efficiency (\%) & $\mathrm{C}_{\mathrm{TASC}}$ & Total annualized system cost (\$) \\
\hline$\beta_{\mathrm{T}}$ & PV temperature coefficient of efficiency & LCE & Levelized cost of energy ( $\$ / \mathrm{kWh})$ \\
\hline $\mathrm{T}_{\mathrm{r}}$ & Temperature at rated PV efficiency $\left({ }^{0} \mathrm{C}\right)$ & $\mathrm{CRF}$ & Capital recovery factor \\
\hline $\mathrm{T}_{\mathrm{c}}$ & Computed ambient temperature $\left({ }^{\circ} \mathrm{C}\right)$ & $\mathrm{L}$ & Life time of the system \\
\hline NOCT & PV normal operating cell temperature $\left({ }^{\circ} \mathrm{C}\right)$ & $\mathrm{T}$ & Time period of analysis \\
\hline $\mathrm{I}_{\mathrm{NOCT}}$ & Solar radiation at NOCT $\left(\mathrm{W} / \mathrm{m}^{2}\right)$ & LPS (t) & Hourly loss in power supply (Wh) \\
\hline $\mathrm{T}_{\mathrm{a}}$ & Ambient temperature $\left({ }^{0} \mathrm{C}\right)$ & $\mathrm{N}_{\text {bat }}$ & $\mathrm{N}_{\text {bat }}$ \\
\hline A & Extra-terrestrial flux (W/m²) & $\mathrm{I}_{\text {bat }}$ & Nominal capacity of BESS (Ah) \\
\hline $\mathrm{k}$ & Optical depth & $\mathrm{V}_{\text {bat }}$ & BESS voltage (Volt) \\
\hline $\mathrm{m}$ & Air mass ratio & $\alpha$ & Cost of each PV unit (\$) \\
\hline $\mathrm{n}$ & Day number of the year & $\beta_{\mathrm{b}}$ & Cost of each battery (\$) \\
\hline$\beta$ & Altitude angle of the sun & $\mathrm{C}_{0}$ & Total fixed cost (\$) \\
\hline $\mathrm{L}$ & Latitude & $\mathrm{E}_{\mathrm{C}, \text { new }}(\mathrm{t})$ & Hourly net cumulative energy (Wh) \\
\hline $\mathrm{H}$ & Hour angle & & \\
\hline$\delta$ & Solar declination angle & Abbreviation & \\
\hline $\mathrm{I}_{\mathrm{BN}}$ & Normal component of solar radiation $\left(\mathrm{Wh} / \mathrm{m}^{2}\right)$ & ESCA & Electric System Cascade Analysis \\
\hline $\mathrm{I}_{\mathrm{D}}$ & Diffused component of solar radiation $\left(\mathrm{Wh} / \mathrm{m}^{2}\right)$ & BESS & Battery Energy Storage System \\
\hline$I_{R}$ & Reflected component of solar radiation $\left(\mathrm{Wh} / \mathrm{m}^{2}\right)$ & FEE & Final Excess Energy \\
\hline$\varnothing$ & Azimuth angle (degree) & LPSP & Loss of Power Supply Probability \\
\hline$\epsilon$ & Tilt angle of the collector (degree) & PoPA & Power Pinch Analysis \\
\hline$\rho$ & Ground reflectance coefficient (\%) & PSO & Particle Swarm Optimization \\
\hline$\beta_{\mathrm{N}}$ & Altitude angle at noon & GA & Genetic Algorithm \\
\hline$N(t)$ & Hourly net surplus energy (Wh) & PSO & Particle Swarm Optimization \\
\hline$\eta_{i n v}$ & Inverter efficiency (\%) & HES & Hybrid Energy System \\
\hline $\mathrm{E}_{1}(\mathrm{t})$ & Hourly primary load demand (Wh) & TA & Tabu Search \\
\hline $\mathrm{C}_{\text {Bat }}(\mathrm{t})$ & Charging energy of BESS (Wh) & SA & Simulated Annealing \\
\hline$\eta_{\text {char }}$ & Charging efficiency of BESS (\%) & GA & Genetic Algorithm \\
\hline $\mathrm{D}_{\mathrm{Bat}}(\mathrm{t})$ & Discharging energy of BESS (Wh) & DOD & Depth of Discharge \\
\hline$\eta_{\text {dischar }}$ & Discharging efficiency of BESS (\%) & SOC & State of Charge of BESS \\
\hline
\end{tabular}


RETscreen, HOMER, HYBRID2, etc. For example, Upadhyay et al. [12] have compared different combinations of HRES with diesel generator to find the most economic configuration using Particle Swarm Optimization (PSO), Maleki et al. [13] have compared artificial intelligence techniques for optimization of Hybrid Energy System (HES) consisting of fuel cell and battery as storage units and found PSO to be the most effective. Katsigiannis et al. [14] have found the optimum generator scheduling to reduce the cost of energy of the HES using Tabu Search (TA) and Simulated Annealing (SA) methods. Paliwal et al. [15] have performed the reliability analysis of isolated HRES for a rural area using PSO. Koutroulis et al. [16] have analysed the optimization of a desalination system fed by PV, WECS and diesel generator using Genetic Algorithm (GA) technique. Bahramara et al. [17] have performed the optimal planning of an isolated HRES using HOMER. Hove et al. [18] have presented economic analysis of a PV and diesel system with the variation in renewable fraction using RETScreen. Singh et al. [19] have compared HRES in grid and islanding mode of operation for a residential load in Mumbai using HOMER. The major drawbacks of these studies are limited time period of 24 hours, simple system modelling, and complex system optimization technique, especially in case of GA, PSO, etc. There are several limitations to the optimization techniques, e.g., for GA approach there is no guarantee of finding the best solution, for fuzzy logic approach estimation of membership function is difficult and time consuming process and software provides results based on the only input range of the user. Therefore, this paper presents a simple and goal oriented ESCA methodology which overcomes some of the flaws in other optimization techniques.

ESCA is a technique which is based on power pinch analysis used during optimization of raw material like heat, mass, carbon and gasses [20]. Wan et al. [21] implemented this method to minimise the outsourced electricity for a grid connected load. Bandyopadhyay et al. [22] implemented power pinch analysis for the design and optimization of isolated energy system. Ho et al. [23] further improved upon this technique and introduced a new iterative method of ESCA for optimisation of non-intermittent source of biomass and energy storage system for distributed energy generation system. Ho et al. [24] further extended his work to optimize an isolated system with intermittent source of PV, where the cascade table analysis helped in PV system size optimization and power pinch analysis was performed to obtain the size of the storage unit. All these works provide a deep insight into the successful implementation of ESCA in optimization of the renewable energy system, but there is scope of improvement.

The common approach in all these studies is having load and geometric climate data for 24 hours only, which has its limitations on practical implementation. Therefore, this paper considers the historical data for a year of load, temperature and solar radiation for optimal system design of an isolated PV generating system using ESCA methodology with constraints of FEE, LPSP and system cost. Unlike other techniques which optimize the system first and then find the most economical solution, in this paper reliability and economic constraints are analysed simultaneously to arrive at the optimized results. Also included in the analysis, is the practical variation of the PV efficiency with temperature and the battery efficiency with state of charge. The solar radiation profile is considered by incorporating the attenuation, diffusion and reflection of the solar beam radiation reaching the PV collector surface. The FEE constraint is used to optimize the BESS. FEE > 0, may lead to accretion in the initial charge of BESS on recursive use thereby over estimating the BESS capacity and FEE $<0$, may lead to depletion in the initial charge of BESS over recursive use which can lead to failure of the system. LPSP constraint is a good indicator of the reliability of the system, which is the main optimization constraint for the PV system planning. The LPSP constraint can be achieved by reducing BESS capacity and/or reducing PV system rating, therefore 
system cost constraint is also incorporated in the analysis to obtain an optimized system configuration with minimum cost. In this work, the load profile considered is for a residential load with latitude and longitude as $40^{\circ}$ $\mathrm{N}$ and $70^{\circ} \mathrm{W}$ respectively. The ESCA algorithm is implemented firstly, with a time period of 288 hours with the constraint of reducing FEE below $100 \mathrm{Wh}$. The load, solar and temperature profile for this analysis are formed by combining 24 hours profile of each month, assuming that the profile remains same for all the days of the month. Therefore, it is a good indicator of how the system would respond to the monthly variations in these parameters. Secondly, ESCA is executed for time period of 8760 hours with the aim to improve the optimized result obtained with LPSP less than $2 \%$ and minimum system cost, for an entire year of system usage. Finally, the optimized result obtained from ESCA are compared to that obtained from HOMER software.

The rest of the paper is organized as follows: Section 2, describes the system architecture and the choice of system storage. Section 3, explains the modelling of system components and solar radiation profile. Section 4, formulates the system cost and reliability parameters. Section 5, describes the ESCA methodology implemented for a time period of 288 hours. Section 6, describes the ESCA methodology implemented for a time period of 8760 hours along with the graphical approach used to find the system with minimum cost. Section 7, the system parameters and details of system component is presented. Section 8, shows the results obtained on implementation of the ESCA methodology which are also compared to that obtained from HOMER. Section 9, concludes the paper signifying the integrity of ESCA methodology.

\section{Isolated PV system architecture}

For this case study, an isolated system as shown in Fig. 1 is considered with PV system and BESS connected to a DC bus. The interface between the DC and AC bus is through a converter which rectifies the DC power generated by the PV panels and stored in battery bank, into AC. On the AC bus, the primary load is connected along with a dummy load. The dummy load has the prime function of absorbing the excess energy generated after catering to the primary load, which cannot be stored in BESS [25]. If the BESS has reached its maximum charge storage capacity, then the excess energy generated by the PV system, after catering the primary load is fed to the connected dummy load. This dummy load can be water heating system or space cooling system, etc. depending on the load area. There are many options available for the storage unit for the PV energy system but the most common storage units are battery and hydrogen energy storage system [26]. Hydrogen energy storage system based on fuel cell is the new upcoming technology with high modularity, low standing losses and longer lifetime, hence making them an attractive storage options for renewable energy storage system [27]. But due to its low energy density, slow dynamics, low efficiency, high cost of equipment and maintenance, tilts the balance towards conventional battery energy storage system. For isolated system, quick switching is required between generating unit and storage system which is provided by the battery storage system. Therefore for the scope of this paper Trojan T-1275 deep cycle Li-ion battery system is used out of the various options available [28], [29].

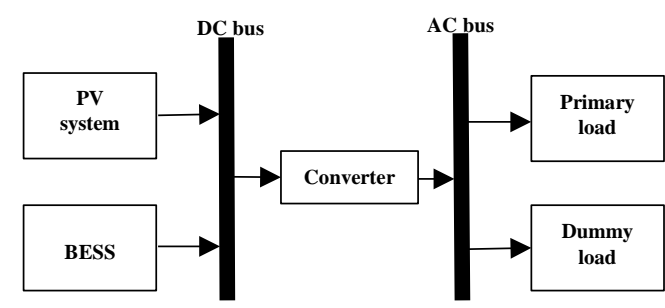

Fig. 1 Block diagram of PV/ battery system 


\section{Modelling of system components}

\subsection{PV model}

For a mono-crystalline PV system, the hourly energy output can be expressed as shown in (1) [26], [30]:

$$
\begin{gathered}
E_{P V}(t)=N_{P V} \times A_{P V} \times \eta_{p v} \times I(t) \\
\eta_{p v}=\eta_{r}\left[1-\beta_{T}\left(T_{c}-T_{r}\right)\right] \\
T_{c}=T_{a}+\left(\frac{N O C T-T_{a, N O C T}}{I_{N O C T}}\right) \times I(t)
\end{gathered}
$$

where, $E_{P V}(t)$ is the hourly energy generated by the PV system in Wh, $N_{P V}$ is the number of PV panels in the system, $\mathrm{A}_{\mathrm{PV}}$ is the area of each PV panel in $\mathrm{m}^{2}, \mathrm{I}(\mathrm{t})$ is the hourly solar radiation falling on the PV panels in Wh/ $\mathrm{m}^{2}$, $\eta_{\mathrm{pv}}$ is the PV panel efficiency calculated from (2), $\eta_{\mathrm{r}}$ is the rated PV panel efficiency, $\beta_{\mathrm{T}}$ is the temperature coefficient of efficiency, $\mathrm{T}_{\mathrm{r}}$ is the temperature for rated PV efficiency in ${ }^{0} \mathrm{C}, \mathrm{T}_{\mathrm{c}}$ is the computed ambient temperature in ${ }^{0} \mathrm{C}$ calculated from (3) [31], NOCT is the normal operating cell temperature in ${ }^{0} \mathrm{C}$, $\mathrm{I}_{\mathrm{NOCT}}$ is the solar radiation at NOCT in $\mathrm{W} / \mathrm{m}^{2}$ and $\mathrm{T}_{\mathrm{a}}$ is the ambient temperature in ${ }^{0} \mathrm{C}$.

\subsection{Solar radiation model}

The amount of solar radiation that reaches the collector surface depends on various factors and cannot be considered constant. The beam portion of solar radiation reaching the earth surface after attenuation from the atmosphere is expressed as shown in (4) [32]:

$$
I_{B}=A \times e^{-k m}
$$

where, $\mathrm{A}$ is the extra-terrestrial flux in $\mathrm{W} / \mathrm{m}^{2}$ expressed by (5), $\mathrm{k}$ is a dimensionless factor called optical depth expressed in (6) and $\mathrm{m}$ is the air mass ratio expressed in (7) [32].

$$
\begin{gathered}
A=1160+75 \sin \left[\frac{360}{365}(n-275)\right] \\
k=0.174+0.035 \sin \left[\frac{360}{365}(n-100)\right] \\
m=\frac{1}{\sin \beta}
\end{gathered}
$$

where,

$$
\begin{gathered}
\sin \beta=\cos L \cos \delta \cos H+\sin L \sin \delta \\
\delta=23.45 \sin \left[\frac{360}{365}(n-81)\right] \\
H=15^{0} \times h
\end{gathered}
$$

where, $\mathrm{n}$ is the day number of the year and $\beta$ is the altitude angle of the sun which is a function of latitude (L), hour angle $(\mathrm{H})$, and solar declination angle $(\delta)$ and h is the number of hours before noon, which is considered positive before noon and negative after noon. After reaching the earth surface, the solar radiation that reaches the collector surface comprises of three components: $\mathrm{I}_{\mathrm{BN}}$ which is the direct beam component falling normally to the collector surface, $I_{D}$ the diffused beam component falling at some angle to the collector surface and $I_{R}$ the reflected beam component falling to the collector surface after reflecting from the ground. They are expressed by (11-15) [33]:

$$
I_{B N}=I_{B} \cos \theta
$$

where,

$$
\begin{gathered}
\cos \theta=\cos \beta \cos \emptyset \sin \epsilon+\sin \beta \cos \epsilon \\
I_{D}=C I_{B}
\end{gathered}
$$


where,

$$
\begin{gathered}
C=0.095+0.04 \sin \left[\frac{360}{365}(n-100)\right] \\
I_{R}=\rho I_{B}(\sin \beta+C)\left(\frac{1-\cos \epsilon}{2}\right)
\end{gathered}
$$

where, $\emptyset$ is the azimuth angle in degree, $\epsilon$ is the tilt angle of the PV collector in degree and $\rho$ is the ground reflectance coefficient. The ideal tilt angle for the collector can be evaluated using (16).

$$
\epsilon=90-\beta_{N}
$$

where, $\beta_{\mathrm{N}}$ is the altitude angle at noon.

\subsection{Battery model}

Whenever the power generation from the PV system exceeds the load demand, excess energy is used to charge the BESS. This energy from the batteries is used to cater the primary load when the power from the PV system is less than the load demand. It is to be emphasised that the power generation from the PV system is firstly provided to primary load and thereafter excess energy is used to charge the BESS [23]. By doing this we prevent conversion loss from DC to AC. The net surplus/deficient supply during a time interval is given by (17) [23] .

$$
N(t)=\left(E_{P V}(t) \times \eta_{\text {inv }}\right)-E_{l}(t)
$$

where, $\mathrm{N}(\mathrm{t})$ is the net surplus energy in the current time step in Wh, $\eta_{\text {inv }}$ is the inverter efficiency and $\mathrm{E}_{\mathrm{l}}(\mathrm{t})$ is the primary load demand in the current time step in Wh. If $\mathrm{N}(\mathrm{t})>0$ then batteries are charged and if $\mathrm{N}(\mathrm{t})<0$ then batteries are discharged. The charging and discharging of the batteries are governed by (18-19) which considers the charging and discharging losses [24] .

$$
\begin{gathered}
C_{\text {Bat }}(t)=\left\{\begin{aligned}
N(t) \times \eta_{\text {char }}, & N(t)>0 \\
0, & N(t) \leq 0
\end{aligned}\right. \\
D_{\text {Bat }}(t)=\left\{\begin{aligned}
\frac{N(t)}{\eta_{\text {dischar }} \times \eta_{\text {inv }}}, & N(t)<0 \\
0, & N(t) \geq 0
\end{aligned}\right.
\end{gathered}
$$

where, $\mathrm{C}_{\mathrm{Bat}}(\mathrm{t})$ is the energy by which BESS is charged in Wh, $\eta_{\text {char }}$ is the charging efficiency of the battery, $\mathrm{D}_{\text {Bat }}(\mathrm{t})$ is the energy by which the BESS is discharged in Wh and $\eta_{\text {dischar }}$ is the discharging efficiency of the battery. As the charging/discharging efficiency is effected by the SOC of BESS therefore, based on the research presented in [34]-[37] and the data sheet provided by the manufacturer [38] variation in efficiency is also considered. The net accumulated energy in the BESS is given by (20) [39].

$$
E_{c}(t)=E_{c}(t-1)+C_{B a t}(t)+D_{B a t}(t)
$$

where, $E_{c}(t)$ is the net accumulated charge in the BESS in the current time interval in Wh and $E_{c}(t-1)$ is the net accumulated charge in the battery in the previous time interval in Wh.

\subsection{Converter model}

The converter forms an essential part of the PV-BESS system as the energy generated by the PV panels and stored in BESS is DC, which needs to be converted into AC to cater the AC load. The rating of the converter/inverter required for the system is governed by (21) [23].

$$
P_{\text {inv }}=P_{L}(\max ) / \eta_{\text {inv }}
$$

where, $\mathrm{P}_{\text {inv }}$ is the inverter rating in Watts, $\mathrm{P}_{\mathrm{L}}(\max )$ is the peak value of the load demand in Watts. The output voltage from the PV system and the BESS are equal to the DC bus voltage, therefore no conversion is required for charging of the battery from PV panels. 


\section{System cost and reliability parameters}

\subsection{Calculating the cost of the system}

The system cost can be evaluated in different ways such as, initial capital cost of the system, the total cost of the system, the total annualized cost of the system or levelized cost of energy. The initial capital cost ( $\mathrm{C}_{\mathrm{ICC}}$ ) includes the initial cost of system components and installation cost. The total cost of the system ( $\left.\mathrm{C}_{\mathrm{TCS}}\right)$ includes the cost of system components, cost of replacement of system components, installation cost and maintenance cost of system throughout the lifetime of the system. The total annualized system cost ( $\left.\mathrm{C}_{\mathrm{TASC}}\right)$ is the total system cost contribution annually, this is used for system which has a line of credit. The levelized cost of energy (LCE) gives the cost of each unit of energy generated by the system. These costs are expressed in (22-27) [40]-[43].

$$
\begin{gathered}
C_{I C C}=N_{P V} *\left(C_{P V, C}+C_{P V, I}\right)+N_{B a t} * C_{B a t, C} \\
C_{T C S}=N_{P V} *\left(C_{P V, C}+C_{P V, M}+C_{P V, I}\right)+N_{B a t} * C_{B a t, N}+C_{B O S}
\end{gathered}
$$

where $\quad C_{B a t, N}=C_{B a t, C} *\left(1+\frac{r}{(1+r)^{5}}+\frac{r}{(1+r)^{10}}+\frac{r}{(1+r)^{15}}+\frac{r}{(1+r)^{20}}\right)+C_{B a t, I}$

where, $\mathrm{CPV}_{\mathrm{P}, \mathrm{C}}$ is the cost of a single $\mathrm{PV}$ panel, $\mathrm{C}_{\mathrm{PV}, \mathrm{M}}$ is the maintenance cost, $\mathrm{C}_{\mathrm{PV}, \mathrm{I}}$ is the cost of installation of $\mathrm{PV}$, $\mathrm{C}_{\mathrm{Bat}, \mathrm{C}}$ is the cost of a single battery, $\mathrm{C}_{\mathrm{Bat}, \mathrm{I}}$ is the installation cost of the battery, $\mathrm{C}_{\mathrm{BOs}}$ is the cost of balance of system and $r$ is the discount rate. The annual cost of system can be found (25-26) [39].

where,

$$
\begin{gathered}
C_{T A S C}=C_{T A C} \times C R F \\
C R F=\frac{r \times(1+r)^{L}}{(1+r)^{L}-1}
\end{gathered}
$$

where, $\mathrm{C}_{\text {TASC }}$ is total annual system cost, $\mathrm{CRF}$ is the capital recovery factor and $\mathrm{L}$ is the life time of the system. In order to calculate the levelized cost of energy (27) [44] can be used.

$$
L C E=\frac{C_{T A S C}}{\sum_{t=0}^{T} E_{l}(t)}
$$

\subsection{Loss of power supply probability}

It is defined as the long term average fraction of the load not supplied by the system. The load will not be satisfied if the power generated by the PV system and the storage is depleted below the allowable limit. LPSP of 1 means the load will never be satisfied and LPSP of 0 means load will always be satisfied. In terms of BESS charge, LPSP is defined (28) [45].

$$
L P S P=\operatorname{Pr}\left\{E_{C}(t) \leq E_{C \min }(t) ; \text { for } t<T\right\}
$$

where, $\mathrm{P}_{\mathrm{r}}$ stands for probability. Implementing (17) to the ESCA methodology applied, we obtain LPSP for the time period of analysis as shown in (29-30) [46].

$$
\begin{gathered}
\operatorname{LPSP}=\frac{\sum_{t=1}^{T} \operatorname{LPS}(t)}{\sum_{t=1}^{T} E_{l}(t)} \\
\text { where, } \quad \operatorname{LPS}(t)=E_{l}(t)-\left(E_{P V}(t)+E_{C}(t-1)-E_{C \text { min }}\right) \times \eta_{\text {inv }}
\end{gathered}
$$

\section{ESCA methodology for time period of 288 hours}

Power pinch analysis forms the guideline in implementing the ECSA methodology. The algorithm of the implemented ESCA methodology is shown in Fig. 2. It is emphasised that the constraint for optimization 
considered is FEE as an alternative to the change in area of PV generating unit, as proposed by Ho et al.[23]. The steps involved in implementing the ESCA methodology are as follows [24]:

Step 1. Data extraction and initial estimation of PV panels.

Step 2. Construct the cascade table for intermittent system.

Step 3. Recalculate the size of PV generating unit with FEE constraint.

Step 4. Check if constraint is satisfied, If not repeat step 2-3.

Step 5. Calculate the size of BESS after constraint is satisfied.

Step 6. Calculate the size of the converter required for the system.

Step 7. Calculate the cost of the system.

For successful implementation of ESCA for optimization of the HRES certain conditions have to be satisfied, which are as follows [47]:

i. $\quad$ Power generated from the PV system is first supplied to load, before storing it in the BESS to reduce conversion losses.

ii. Losses during charging and discharging of the battery should be considered.

iii. Amount of energy stored at the starting $(\mathrm{t}=0)$ and end of the time cycle $(\mathrm{t}=288$, in this case) should almost remain same. This prevents aggregation/depletion of initial charge on cyclic use.

iv. Accumulation of charge $\mathrm{E}_{\mathrm{C}}$, in the BESS should always be positive and above the DOD limit.

v. Load, temperature and solar radiation remains constant for each time interval (1 hour for this study).

\subsection{Data extraction and initial size estimation}

The first step of implementing ESCA is data extraction which include the following data: (i) Time period of analysis (ii) Hourly load demand (iii) Hourly ambient temperature (iv) Hourly average solar irradiance (v) Rated PV module efficiency (vi) Area of each PV module used (vii) Inverter efficiency (viii) Type and characteristic of battery (ix) Battery charging and discharging efficiencies (x) Depth of discharge of the battery (xi) Initial estimate of PV panels. The optimization algorithm implemented is immune to the initial estimate of the PV panels and can give the optimum value for both over-estimation and under-estimation of the PV panels. The only effect of the initial estimate is that the number of iterations required to reach to the optimum result may vary.

\subsection{Construction of cascade table}

Once the data is extracted, the next step is to form the cascade table after which the power pinch analysis is performed. The method of constructing the table is as follows:

Column 1. It consists of the time period arranged in ascending order. The time interval considered for analysis is 1 hour.

Column 2. The hourly load demand in Wh denoted by $\mathrm{E}_{\mathrm{l}}(\mathrm{t})$.

Column 3. The hourly ambient temperature.

Column 4. The hourly solar radiation in $\mathrm{Wh} / \mathrm{m}^{2}$, denoted by I (t), calculated using (11-16).

Column 5. The hourly energy generated by the PV generating unit in Wh, calculated using (1).

Column 6. The net demand of energy in Wh, calculated using (17).

Column 7. It represents the charging status of BESS. If $N(t)>0$ the battery is charged using (18).

Column 8. It represents the discharging status of BESS. If $\mathrm{N}(\mathrm{t})<0$ the battery is discharged using (19). 
Column 9. Net accumulated energy or the current status of BESS is calculated using (20). During initial analysis $\mathrm{E}_{\mathrm{c}}(\mathrm{t}=0)$ is considered zero.

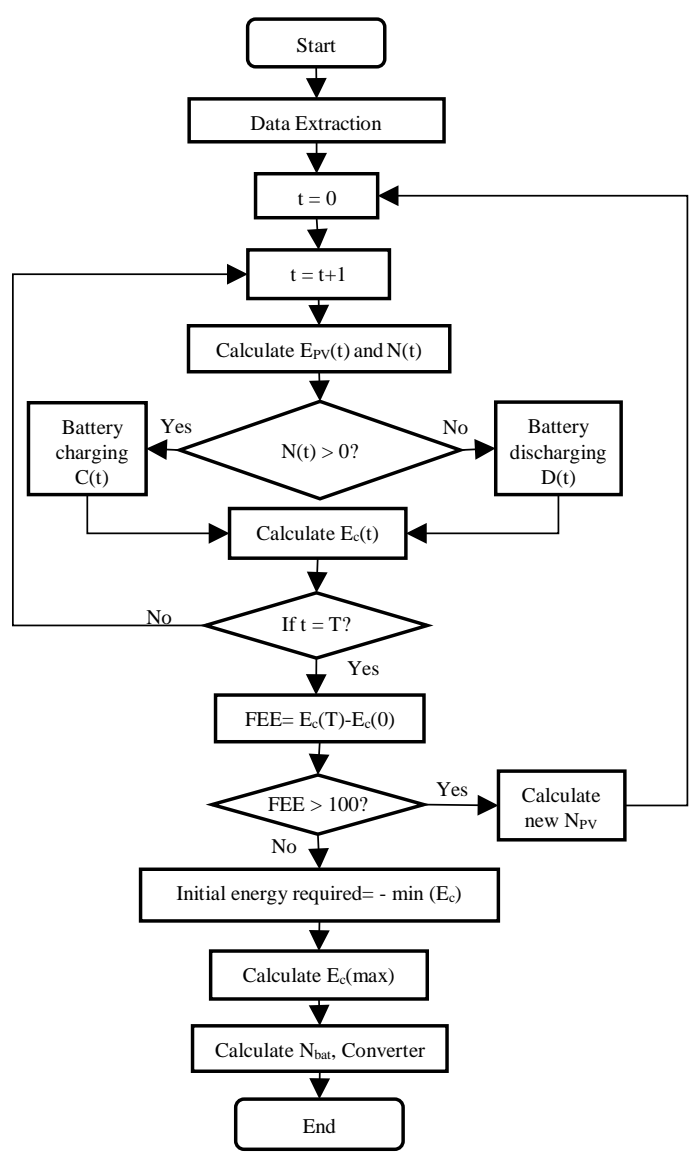

Fig. 2 Flowchart of implemented ESCA algorithm

\subsection{Recalculating the size of PV system}

The new size of the number of PV panels based on the FEE constraint is calculated by (32) or (33). The advantage of using (32) is faster realisation of the FEE constraint irrespective of the initial $\mathrm{N}_{\mathrm{PV}}$ estimation. It may lead to infinite iteration in cases where FEE constraint is set too small/large in comparison to the each system component rating (each PV module rating in this case). In contrast using (33) provides definite realisation of the FEE constraint, but may require more iteration based on the initial $\mathrm{N}_{\mathrm{PV}}$ estimation.

$$
\begin{gathered}
F E E=E_{c}(T)-E_{c}(0) \\
N_{P V, \text { new }}=N_{P V, \text { old }}-\left(\frac{F E E}{\sum_{0}^{T} E_{P V} \times \eta_{P V} \times \eta_{\text {inv }}}\right) \\
N_{P V, \text { new }}=\left\{\begin{array}{l}
N_{p v, o l d}-1, F E E>0 \\
N_{p v, \text { old }}+1, F E E<0
\end{array}\right.
\end{gathered}
$$

\subsection{Calculating BESS size}

Once the constraint of FEE is met the second condition of having all the values of $E_{c}(t)>0$ has to be satisfied, which is inspired from the concept of Power Pinch Analysis (PoPA). For PoPA, the most negative value of the accumulated energy $\left(E_{c}\right)$ is found from the cascaded table. The time at which this value is obtained, is the pinch point of the analysis. $E_{c}(t=0)$ is updated with this value and a new accumulated energy is found with, $E_{c, n e w}(t=$ 
$0)=-E_{c}\left(t=t_{\text {pinch }}\right)$. The maximum value of the new accumulated energy is used to find the BESS size using (31) [24].

$$
N_{\text {Bat }}=\frac{E_{C, \text { new }}(\max )}{I_{\text {bat }} \times V_{\text {bat }} \times D O D}
$$

where $\mathrm{N}_{\text {bat }}$ is the number of batteries required, $\mathrm{I}_{\text {bat }}$ is nominal capacity of battery in Ah, $\mathrm{V}_{\text {bat }}$ is the voltage of BESS in Volts, DOD is the depth of discharge. The battery energy management strategy is shown in Fig. 3, where SOC is state of charge of BESS.

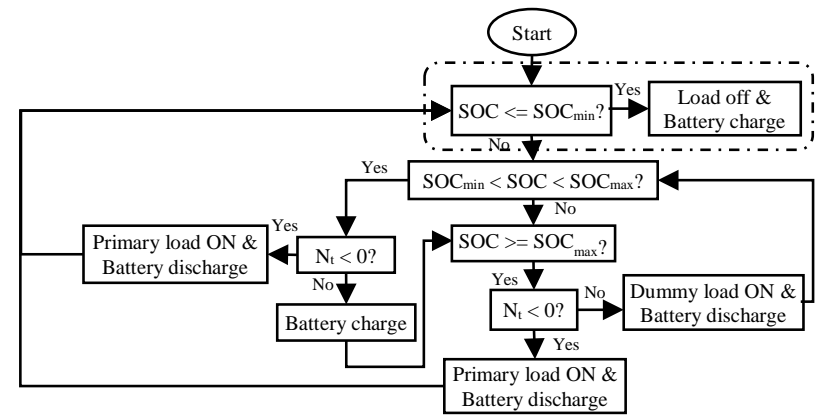

Fig. 3 Battery energy management strategy

\section{ESCA methodology for time period of 8760 hours}

ESCA is implemented for a year to obtain more accurate result. The constraint used for the optimization is LPSP and the system cost. The steps involved are as follows:

Step 1. Data extraction, set $\mathrm{N}_{\text {bat }}=1$, initial estimation of $\mathrm{N}_{\mathrm{PV}}$.

Step 2. Construct the cascade table for intermittent system.

Step 3. Recalculate the size of PV generating unit with LPSP constraint, using (32) or (33) with FEE replaced with LPSP.

Step 4. Tabulate $\mathrm{N}_{\text {bat }}$, optimized $\mathrm{N}_{\mathrm{PV}}$ and the cost of the system for the current configuration.

Step 5. Increment $\mathrm{N}_{\text {bat }}$ and repeat the steps (2-4) until the $\mathrm{N}_{\mathrm{PV}}$ obtained is recursive.

Step 6. Obtain the configuration with minimum cost.

Step 7. Calculate the size of the converter required for the system.

\subsection{Obtaining the system configuration with minimum cost}

The different configurations obtained only satisfy the LPSP constraint. In order to obtain the configuration with minimum cost a graphical approach is preferred. The system cost can be estimated using (35) [45].

$$
C=\alpha N_{P V}+\beta_{b} N_{b a t}+C_{0}
$$

where, $\alpha$ is the cost of each PV unit, $\beta_{\mathrm{b}}$ is the cost of each battery and $\mathrm{C}_{0}$ is the total fixed cost which includes the cost of installation and designing of the system. The condition obtained for optimum solution with minimum cost for a given LPSP is shown in (36) [45]:

$$
\frac{\partial N_{P V}}{\partial N_{b a t}}=-\frac{\beta}{\alpha}
$$

This solution is explained by the theoretical graph shown in Fig. 4 [45] where the slope of the line is $-\beta / \alpha$ and the point of intersection ' $Q$ ' signifies the solution. 


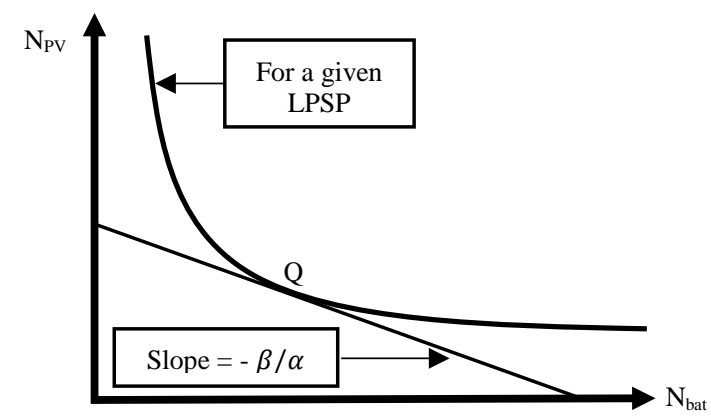

Fig. 4 Theoretical plot of $\mathrm{N}_{\mathrm{PV}}$ and $\mathrm{N}_{\text {bat }}$ for a given LPSP

\section{Case study}

The improved ESCA methodology is implemented for a residential load with latitude and longitude as $40^{\circ} \mathrm{N}$ and $70^{0} \mathrm{~W}$ respectively. The monthly load profile of the location used is shown in Fig. 5 (a) [48]. The load profile for each month is obtained by averaging the loads of all the days of a month, hence obtaining singular hourly load profile of 24 hours for each month. The technical and cost information of the PV, batteries and converter used are shown in Table 1. ESCA is implemented twice, firstly for $\mathrm{T}=288$ hours with optimization constraint of FEE = 100 Wh and no loss of power, secondly, for $\mathrm{T}=8760$ hours with multi constraint optimization of LPSP $=2 \%$ and minimum system cost. For the optimization of PV panels (33) is considered. The results are later compared with that obtained from HOMER to signify the credibility of the ESCA methodology.

Table 1 Parameters of components used in the system [26], [30], [38], [49]

\begin{tabular}{|c|c|c|c|}
\hline \multicolumn{2}{|c|}{ PV parameters } & \multicolumn{2}{|c|}{ Battery parameters } \\
\hline Type & Mono-crystalline & Charge capacity & $220 \mathrm{Ah}$ \\
\hline Area of each panel & $1.10 \mathrm{~m}^{2}$ & Voltage & $12 \mathrm{~V}$ \\
\hline Power of a single panel & $120 \mathrm{Wp}$ & Rated charging efficiency & $90 \%$ \\
\hline Rated module efficiency & $15 \%$ & Rated discharging efficiency & $90 \%$ \\
\hline Temp. coefficient of efficiency & 0.0045 & Depth of discharge & $90 \%$ \\
\hline NOCT & $55^{0} \mathrm{C}$ & Cost of battery & $\$ 700$ \\
\hline Temperature at rated efficiency & $25{ }^{0} \mathrm{C}$ & Life span & 5 years \\
\hline Solar radiation at NOCT & $800 \mathrm{~W} / \mathrm{m}^{2}$ & \multicolumn{2}{|c|}{ Converters parameters } \\
\hline Cost of each panel & $\$ 135$ & Rating of each converter & $600 \mathrm{~W}$ \\
\hline Maintenance cost of each panel & $\$ 15$ & Cost of each unit & $\$ 150$ \\
\hline Installation cost & $\$ 200$ & Life span & 25 years \\
\hline Cost of balance of system & $\$ 600$ & \multicolumn{2}{|c|}{ Time analysis characteristics } \\
\hline \multirow{2}{*}{ Life span } & \multirow{2}{*}{25 years } & Time period interval & 1 hour \\
\hline & & Time period & $\mathrm{T}=288 \& \mathrm{~T}=8760$ \\
\hline
\end{tabular}

\section{Results and discussion}

\subsection{Obtaining the solar radiation profile}

The beam radiation for the case is obtained using (4-10). But the actual radiation that reaches the collector surface is diminished due to diffusion and reflection. The solar radiation profile for each month obtained after considering these factors is shown in Fig. 5 (b). The solar profile of the entire year for the site can be obtained using (4-16). As an example, the components of solar irradiance for the month of March is shown in Table 2, from which the 
different components of radiation profile and the difference between the beam solar radiation and the actual solar radiation reaching the collector surface can be assessed. The PV collector is considered tilted toward south with its tilt angle changing every month as showing Table 3.

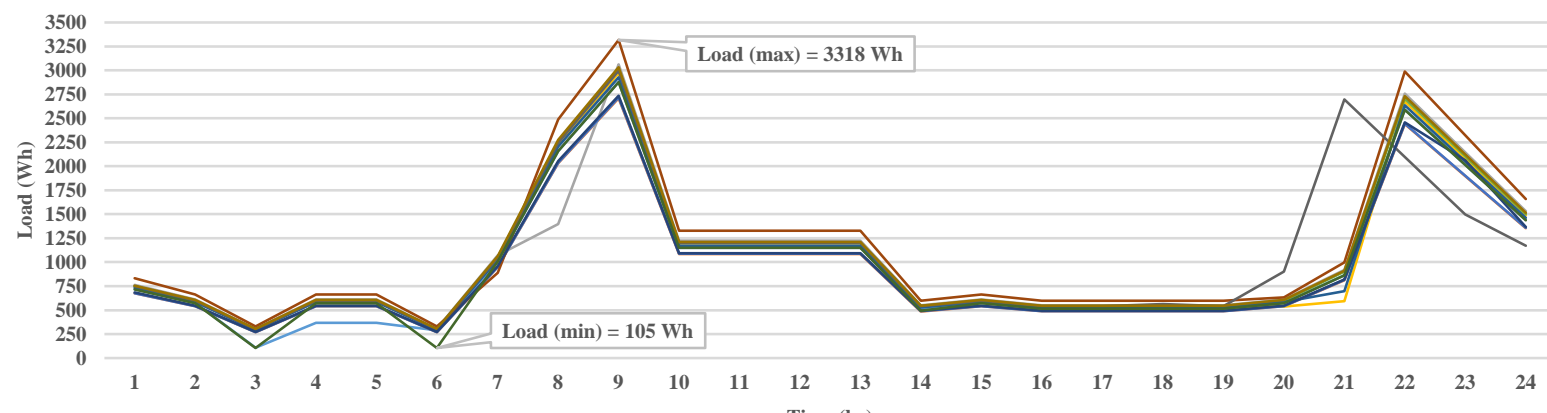

Time (hr
(a)

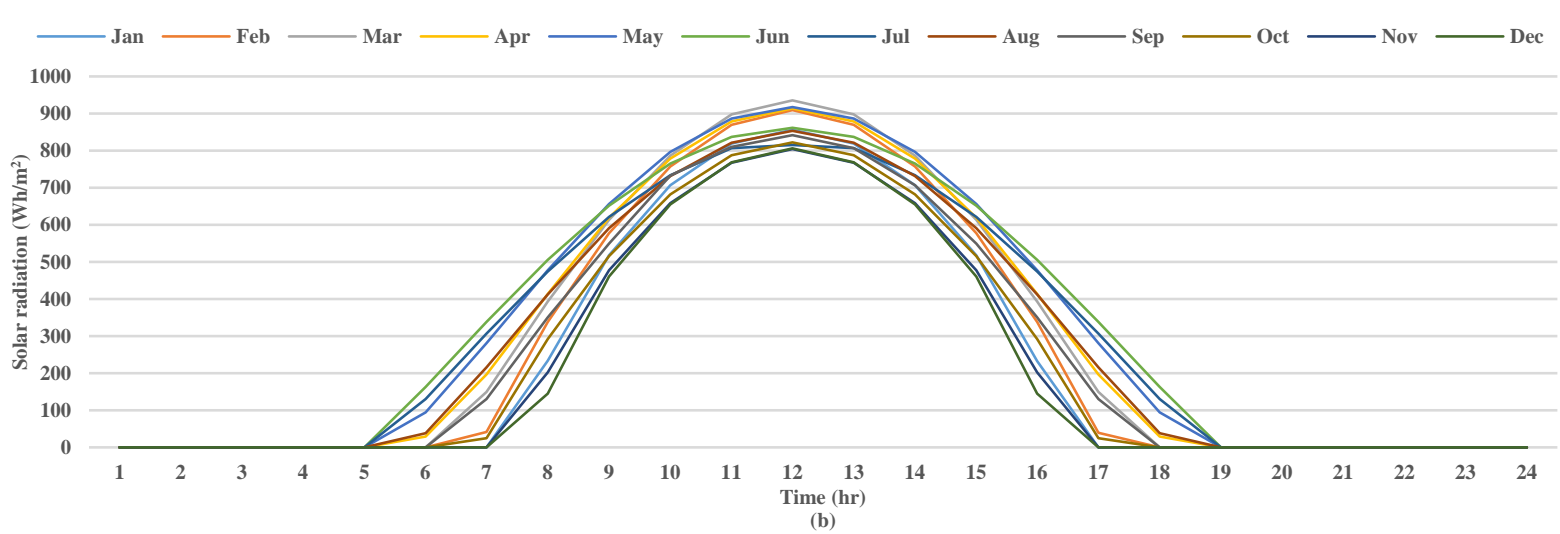

Fig. 5 (a) Hourly load profile in Wh (b) Hourly solar radiation profile reaching the collector in Wh/m²

\subsection{Implementation of ESCA for $\mathbf{T}=\mathbf{2 8 8}$ hours.}

ESCA is initially implemented for time period of 288 hours with an initial assumption of $\mathrm{N}_{\mathrm{PV}}=30$ and zero initial charge in the BESS. The aim of the algorithm is to find the optimized size of $\mathrm{N}_{\mathrm{PV}}$ and $\mathrm{N}_{\mathrm{bat}}$ for a FEE constraint of $100 \mathrm{Wh}$ and no loss of power. On successful implementation of ESCA, the algorithm converges after 79 iterations when FEE $=97 \mathrm{Wh}$ is obtained, the optimized result of $\mathrm{N}_{\mathrm{PV}}=42, \mathrm{~N}_{\mathrm{bat}}=14$, minimum initial charge of $10990 \mathrm{Wh}$ (SOC of $~ 30 \%$ ) in BESS and FEE $=97 \mathrm{Wh}$ is obtained. The pinch point of the analysis is obtained at $\mathrm{t}=32$, which represents the month of February, the cascade table for this month is presented in Table 4. The energy generated by PV panels along with the load demand is shown in Fig. 6. The variation of PV module and battery efficiency is also considered and is shown in Fig. 7. On power pinch point energy adjustment and considering the depth of discharge of $10 \%$ the battery bank size is obtained. The variation in cumulative energy of the BESS for the system with the optimum configuration obtained is shown in Fig. 8 and the state of charge of the BESS along with its histogram is presented in Fig. 9. 
Table 2 Components of solar radiation profile for the month of March

\begin{tabular}{|c|c|c|c|c|c|c|}
\hline Time & $\mathbf{I}_{\mathrm{B}}\left(\mathrm{W} / \mathrm{m}^{2}\right)$ & $\mathbf{I}_{\mathrm{BN}}\left(\mathrm{W} / \mathbf{m}^{2}\right)$ & $I_{D}\left(W / m^{2}\right)$ & $I_{R}\left(W / m^{2}\right)$ & $\begin{array}{c}\mathbf{I}_{\text {actual }}\left(\mathbf{I}_{\mathrm{BN}}+\mathbf{I}_{\mathrm{D}}+\mathbf{I}_{\mathrm{R}}\right) \\
\left(\mathrm{W} / \mathbf{m}^{2}\right)\end{array}$ & $\begin{array}{l}\text { Variation } \\
\left(\mathrm{I}_{\mathrm{B}}-\mathrm{I}_{\text {actual }}\right)\end{array}$ \\
\hline 1 & 0 & 0 & 0.00 & 0.00 & 0.00 & 0.00 \\
\hline 2 & 0 & 0 & 0.00 & 0.00 & 0.00 & 0.00 \\
\hline 3 & 0 & 0 & 0.00 & 0.00 & 0.00 & 0.00 \\
\hline 4 & 0 & 0 & 0.00 & 0.00 & 0.00 & 0.00 \\
\hline 5 & 0 & 0 & 0.00 & 0.00 & 0.00 & 0.00 \\
\hline 6 & 0 & 0 & 0.00 & 0.00 & 0.00 & 0.00 \\
\hline 7 & 168 & 129.78 & 16.92 & 2.75 & 149.45 & 18.55 \\
\hline 8 & 438 & 338.35 & 44.10 & 11.23 & 393.69 & 44.31 \\
\hline 9 & 677 & 522.98 & 68.17 & 22.73 & 613.88 & 63.12 \\
\hline 10 & 862 & 665.89 & 86.79 & 34.18 & $\begin{array}{l}786.87 \\
\end{array}$ & 75.13 \\
\hline 11 & 979 & 756.27 & 98.57 & 42.57 & 897.42 & 81.58 \\
\hline 12 & 1019 & 787.17 & 102.60 & 45.64 & 935.42 & 83.58 \\
\hline 13 & 979 & $\begin{array}{l}756.27 \\
\end{array}$ & 98.57 & 42.57 & 897.42 & 81.58 \\
\hline 14 & 862 & 665.89 & 86.79 & 34.18 & 786.87 & 75.13 \\
\hline 15 & 677 & 522.98 & 68.17 & 22.73 & 613.88 & 63.12 \\
\hline 16 & 438 & 338.35 & 44.10 & 11.23 & 393.69 & 44.31 \\
\hline 17 & 168 & 129.78 & 16.92 & 2.75 & 149.45 & 18.55 \\
\hline 18 & 0 & 0 & 0.00 & 0.00 & 0.00 & 0.00 \\
\hline 19 & 0 & 0 & 0.00 & 0.00 & 0.00 & 0.00 \\
\hline 20 & 0 & 0 & 0.00 & 0.00 & 0.00 & 0.00 \\
\hline 21 & 0 & 0 & 0.00 & 0.00 & 0.00 & 0.00 \\
\hline 22 & 0 & 0 & 0.00 & 0.00 & 0.00 & 0.00 \\
\hline 23 & 0 & 0 & 0.00 & 0.00 & 0.00 & 0.00 \\
\hline 24 & 0 & 0 & 0.00 & 0.00 & 0.00 & 0.00 \\
\hline
\end{tabular}

Table 3 Tilt angle for south facing PV collector

\begin{tabular}{|l|c|c|c|c|c|c|c|c|c|c|c|c|}
\hline Month & Jan & Feb & Mar & Apr & May & Jun & Jul & Aug & Sep & Oct & Nov & Dec \\
\hline Angle & $60^{0}$ & $50^{0}$ & $40^{\circ}$ & $30^{0}$ & $20^{\circ}$ & $0^{0}$ & $0^{0}$ & $20^{0}$ & $40^{0}$ & $50^{\circ}$ & $60^{0}$ & $60^{\circ}$ \\
\hline
\end{tabular}

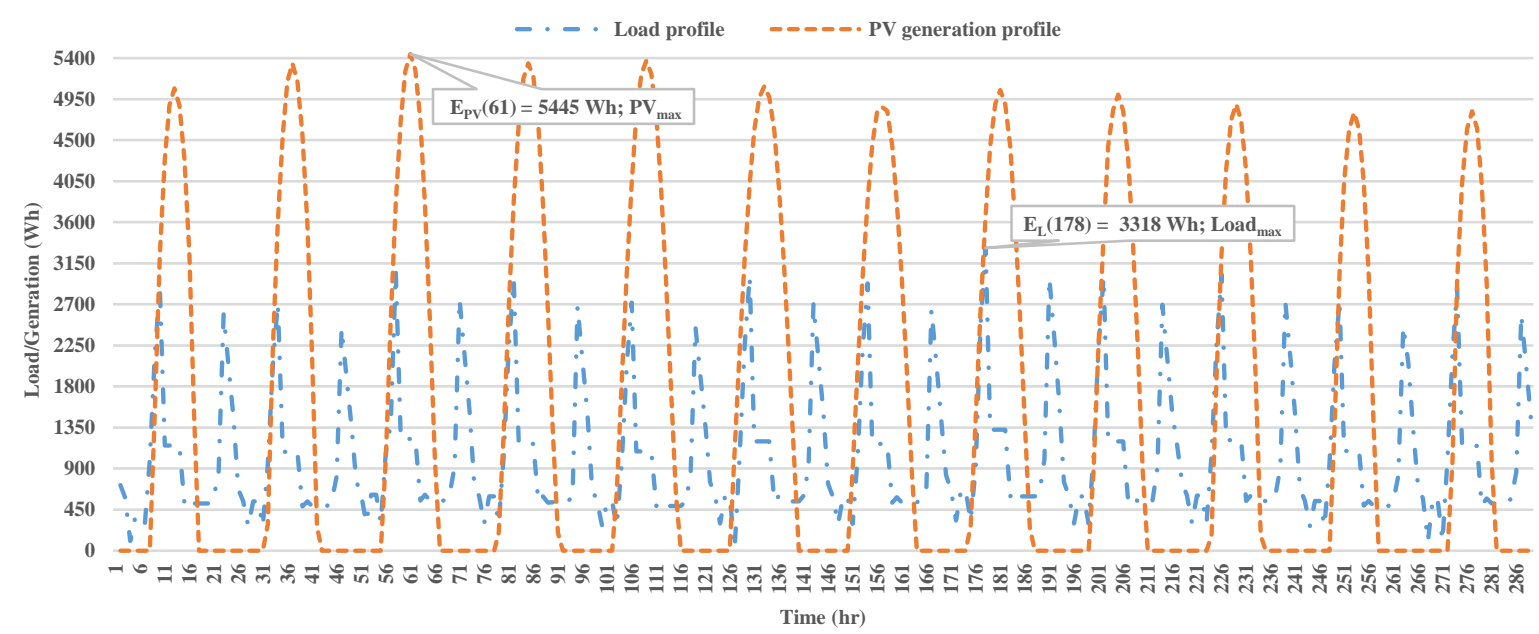

Fig. 6 Power generation of PV and load demand 


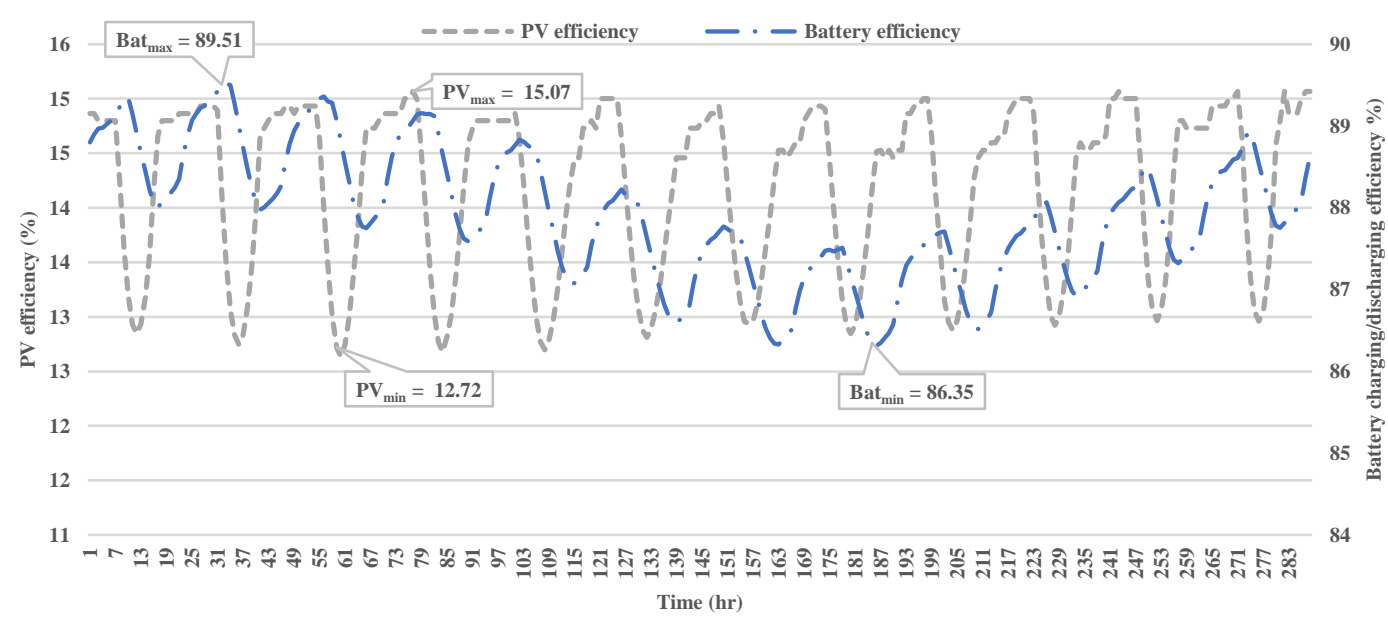

Fig. 7 Variation of PV and battery efficiencies

Table 4 Cascade table obtained for the month of February with $N_{P V}=42$ and $N_{\text {bat }}=14$

\begin{tabular}{|c|c|c|c|c|c|c|c|c|c|}
\hline $\begin{array}{l}\text { Time } \\
\text { (Hr) }\end{array}$ & $\begin{array}{c}E_{L} \\
(W h)\end{array}$ & $\begin{array}{c}\text { Temperature } \\
\left({ }^{0} \mathrm{C}\right)\end{array}$ & $\mathbf{I}\left(\mathbf{W} / \mathbf{m}^{2}\right)$ & $E_{P V}(W h)$ & $\mathbf{N}$ (Wh) & $\mathrm{C}_{\text {bat }}(\mathrm{Wh})$ & $D_{\text {bat }}(W h)$ & $E_{C}(W h)$ & $\begin{array}{l}E_{C, \text { new }} \\
(\text { Wh) }\end{array}$ \\
\hline 25 & 678 & 27 & 0 & 0 & -678 & 0 & -846 & -3536 & 3758 \\
\hline 26 & 540 & 27 & 0 & 0 & -540 & 0 & -673 & -4209 & 3085 \\
\hline 27 & 270 & 26 & 0 & 0 & -270 & 0 & -336 & -4545 & 2749 \\
\hline 28 & 540 & 26 & 0 & 0 & -540 & 0 & $\begin{array}{l}-672 \\
\end{array}$ & -5217 & 2076 \\
\hline 29 & 540 & 26 & 0 & 0 & -540 & 0 & -672 & -5889 & 1405 \\
\hline 30 & 270 & 26 & 0 & 0 & -270 & 0 & -336 & -6224 & 1069 \\
\hline 31 & 948 & 25 & 42 & 288 & -703 & 0 & $\begin{array}{l}-873 \\
\end{array}$ & -7098 & 196 \\
\hline 32 & 2031 & 25 & 338 & 2204 & -158 & $\mathbf{0}$ & -196 & -7294 & $\mathbf{0}$ \\
\hline 33 & 2709 & 25 & 577 & 3601 & 352 & 284 & 0 & -7010 & 284 \\
\hline 34 & 1083 & 30 & 758 & 4565 & 2797 & 2253 & 0 & -4757 & 2537 \\
\hline 35 & 1083 & 31 & 870 & 5147 & 3292 & 2645 & 0 & -2112 & 5182 \\
\hline 36 & 1083 & 30 & 909 & 5341 & 3457 & 2769 & 0 & 658 & 7951 \\
\hline 37 & 1083 & 30 & 870 & 5145 & 3290 & 2628 & 0 & 3285 & 10579 \\
\hline 38 & 486 & 30 & 758 & 4565 & 3394 & 2703 & 0 & 5989 & 13282 \\
\hline 39 & 540 & 30 & 577 & 3576 & 2500 & 1986 & 0 & 7975 & 15268 \\
\hline 40 & 489 & 30 & 338 & 2174 & 1359 & 1077 & 0 & 9051 & 16345 \\
\hline 41 & 489 & 29 & 39 & 263 & -265 & 0 & -335 & 8716 & 16010 \\
\hline 42 & 489 & 29 & 0 & 0 & -489 & 0 & -617 & 8099 & 15393 \\
\hline 43 & 489 & 28 & 0 & 0 & -489 & 0 & -617 & 7482 & 14775 \\
\hline 44 & 540 & 27 & 0 & 0 & -540 & 0 & -681 & 6801 & 14095 \\
\hline 45 & 810 & 27 & 0 & 0 & -810 & 0 & -1021 & 5780 & 13074 \\
\hline 46 & 2439 & 27 & 0 & 0 & -2439 & 0 & -3070 & 2710 & 10004 \\
\hline 47 & 1896 & 26 & 0 & 0 & -1896 & 0 & -2379 & 331 & 7625 \\
\hline 48 & 1353 & 26 & 0 & 0 & -1353 & 0 & -1693 & -1362 & 5931 \\
\hline
\end{tabular}




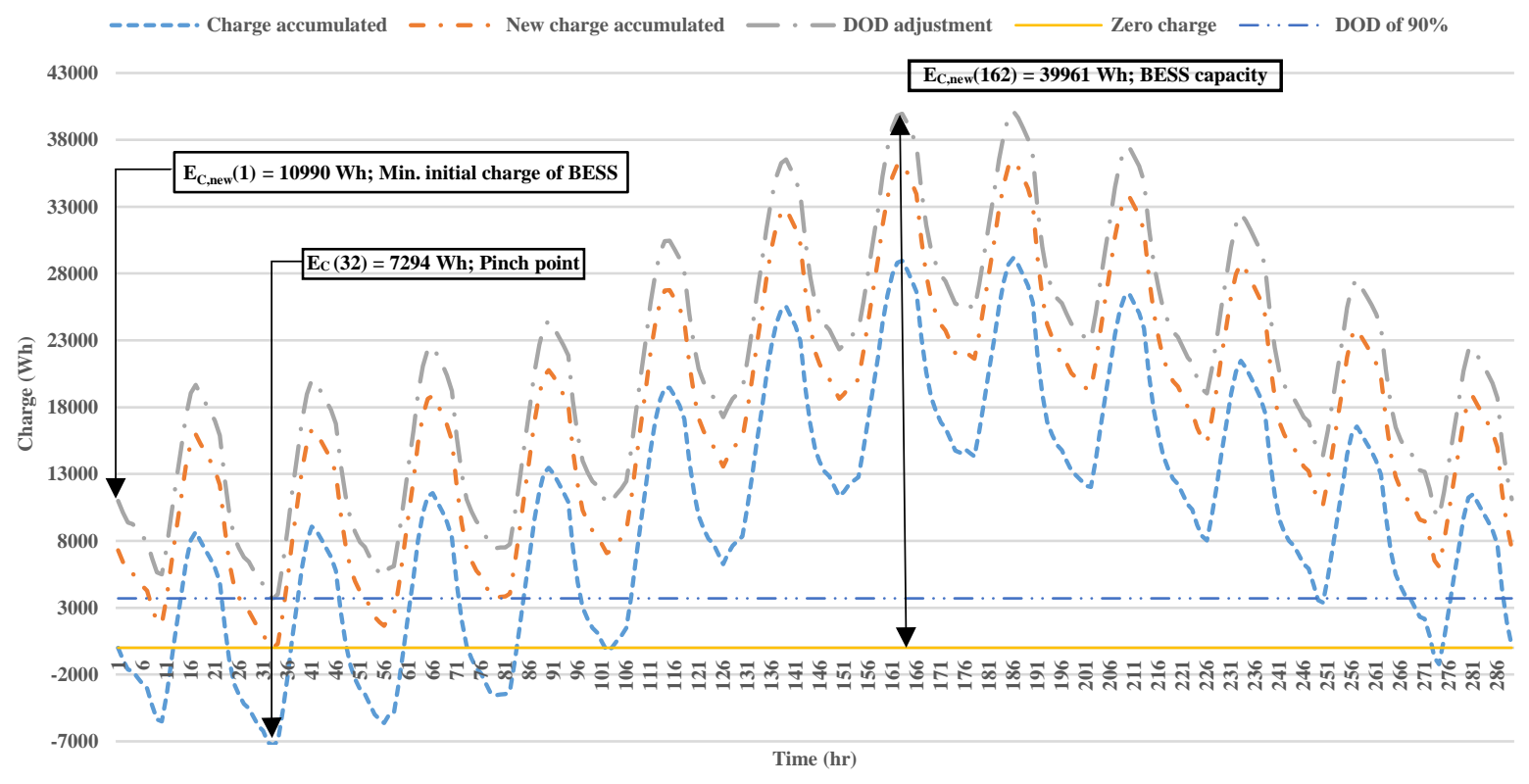

Fig. 8 Variation in charge accumulated in BESS
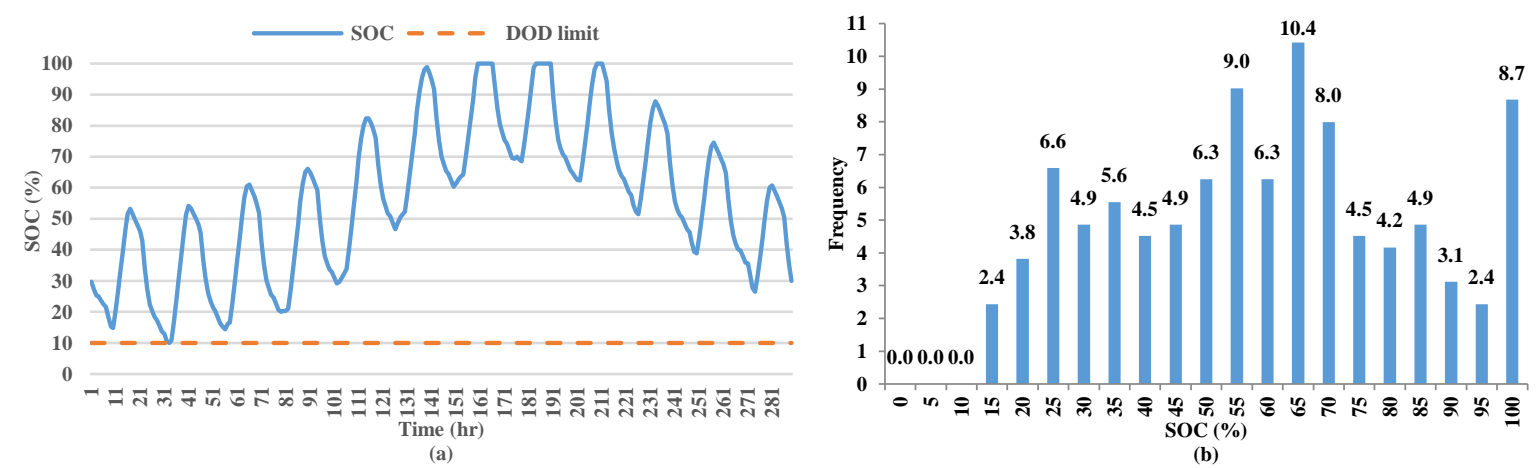

Fig. 9 (a) Variation in state of charge of BESS (b) Histogram for the charge percentage of BESS for T=288 hrs.

As seen from Fig. 7, as the temperature varies the efficiency of the PV panels varies from $12.72 \%$ to $15.07 \%$. Also as the SOC of BESS varies, variation in charging and discharging efficiency is observed, which varies from $86.35 \%$ to $89.51 \%$. As seen from Fig. 9, due to depth of discharge adjustment the SOC of BESS is never below $10 \%$. When the charge of battery becomes $100 \%$ the dummy load is switched on to prevent overcharging of the batteries.

\subsection{Implementation of ESCA for $\mathbf{T}=\mathbf{8 7 6 0}$ hours}

The optimized result obtained for $\mathrm{T}=288$ hours analysis are extrapolated for $\mathrm{T}=8760$ hours. The load and solar profile for entire year is considered, with assumption that the profiles remain identical through the month. When system is run with $\mathrm{N}_{\mathrm{PV}}=42$ and $\mathrm{N}_{\text {bat }}=14$, LPSP of $6.59 \%$ is obtained which is inadmissible, this also shows that time period of analysis strongly affects the optimized result obtained. Therefore, a new approach is considered where the $\mathrm{N}_{\mathrm{PV}}$ is found using ESCA methodology for a range of BESS capacities with LPSP constraint. The initial size of the BESS is fixed for each iteration and the initial charge is assumed to be $30 \%$ SOC as obtained in the previous analysis. The tolerance limit for the LPSP constraint is set at $2 \%$. The variation in LPSP with increase in $\mathrm{N}_{\mathrm{PV}}$ for a fixed value of $\mathrm{N}_{\text {bat }}$ is shown in Fig. 10. 


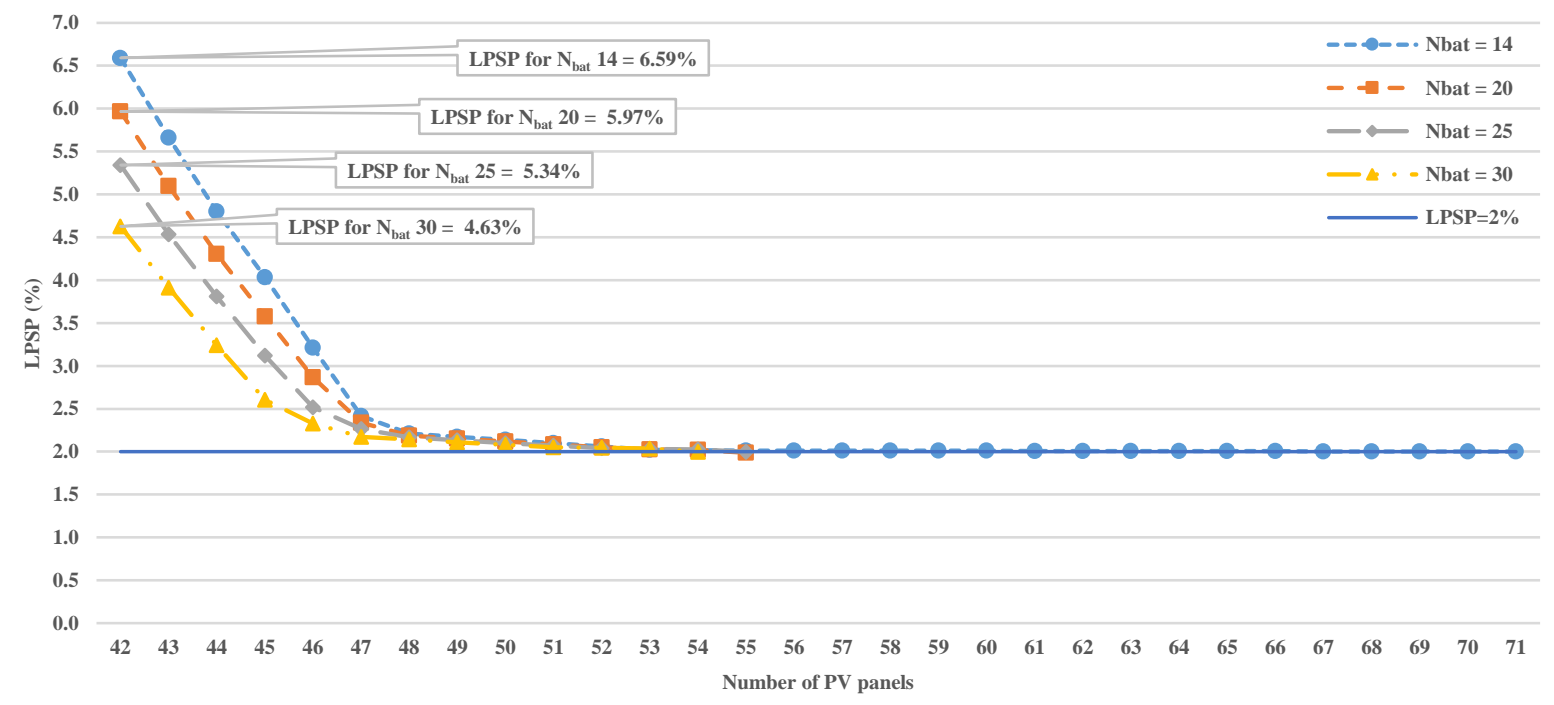

Fig. 10 LPSP and $\mathrm{N}_{\mathrm{PV}}$ variation for given $\mathrm{N}_{\text {bat }}$

It is seen from the Fig. 10, as the size of BESS increases the convergence rate of LPSP increases. For example, for $\mathrm{N}_{\text {bat }}$ equal to 14, 20, 25 and 30, LPSP constraint is satisfied for $\mathrm{N}_{\mathrm{PV}}$ equal to 71, 55, 54, and 54 respectively and iterations required for convergence are 31, 14, 14 and 13 respectively, signifying the reduction in number of PV panels required for achieving the LPSP constraint as the BESS capacity is increased. The configuration with minimum cost is obtained using the graphical method as explained in section 6.1. The plot of variation of $N_{P V}$ and $\mathrm{N}_{\text {bat }}$ for fixed value of LPSP $<2 \%$ is shown in Fig. 11, which is obtained by varying the $\mathrm{N}_{\text {bat }}$ from 1 to 35 while obtaining the optimized $\mathrm{N}_{\mathrm{PV}}$ satisfying the LPSP constraint.

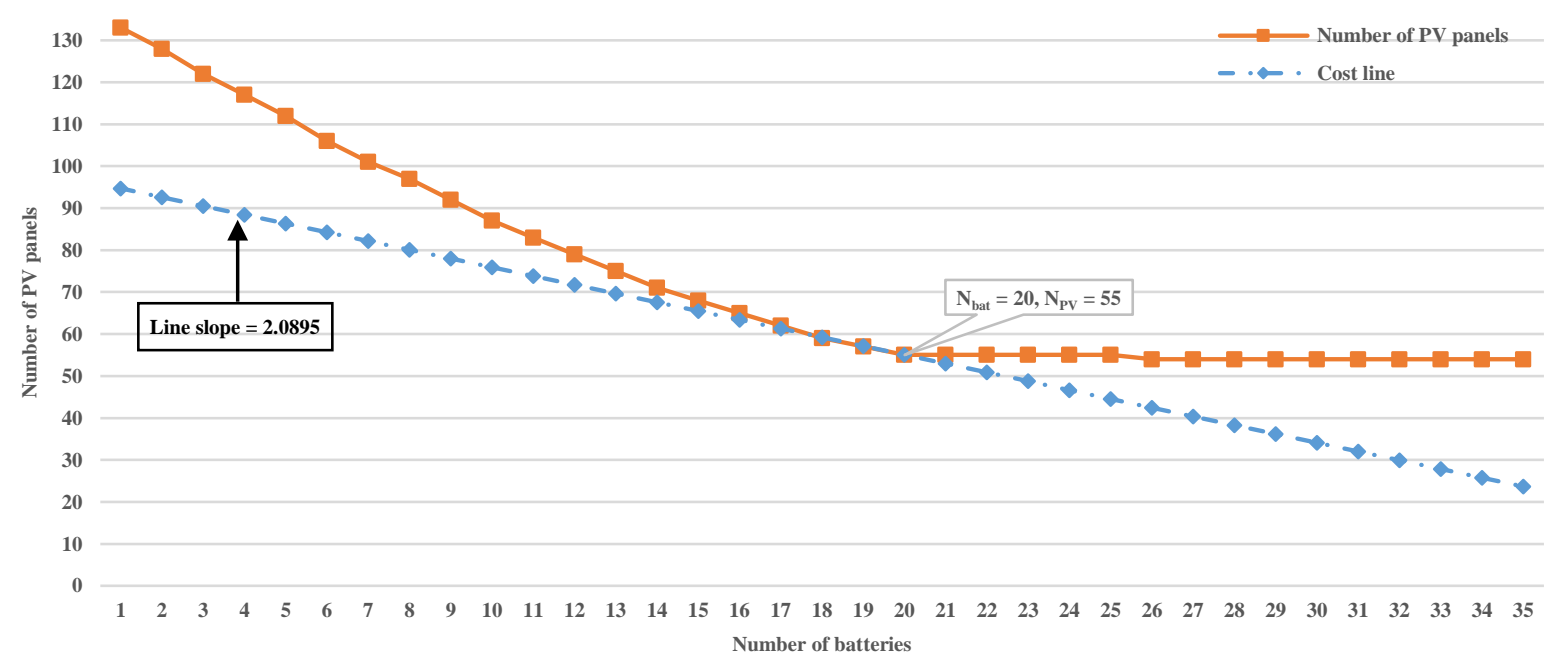

Fig. 11 Plot of $\mathrm{N}_{\text {bat }}$ and $\mathrm{N}_{\mathrm{PV}}$ for LPSP $<2 \%$

The most optimal solution obtained is, $\mathrm{N}_{\mathrm{PV}}=55$ and $\mathrm{N}_{\text {bat }}=20$ for a permissible LPSP of $1.85 \%$. The monthly PV generation for the optimized system is presented in Fig. 12, the SOC of the BESS is shown in Fig. 13 (a) and the histogram of the charge percentage of the BESS is shown in Fig. 13 (b). 


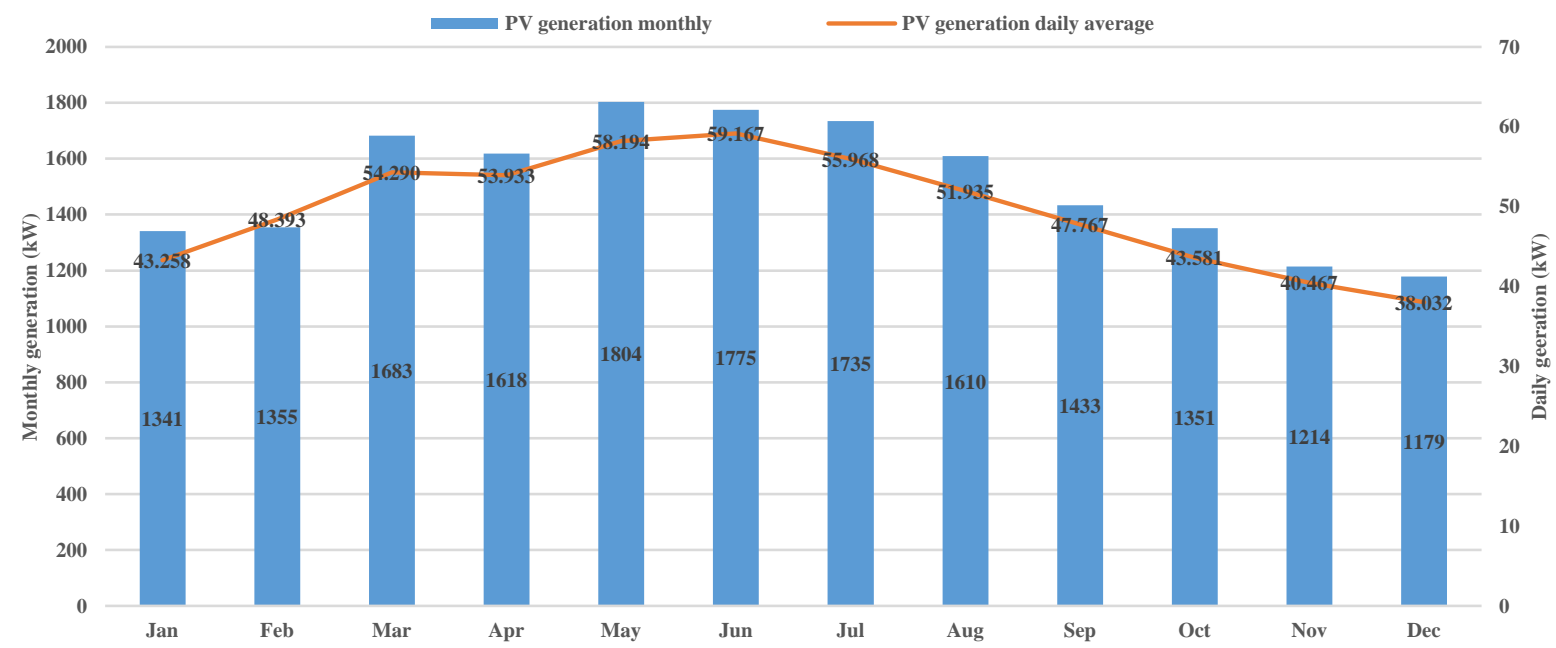

Fig. 12 Monthly and daily average generation from PV
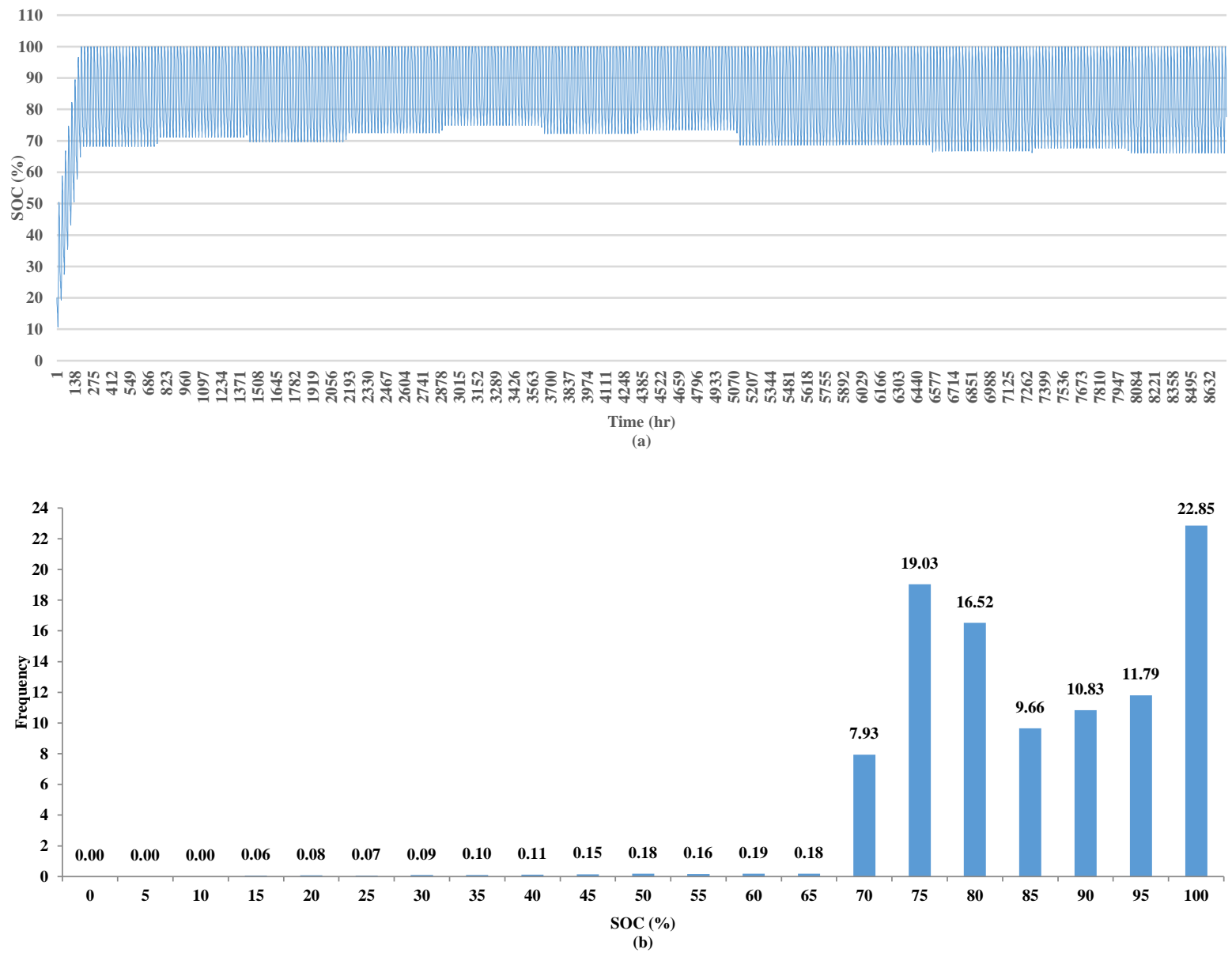

Fig. 13 (a) State of charge of BESS (b) Histogram for the charge percentage of BESS for T = 8760 hrs.

\subsubsection{Comparison of obtained results with HOMER software}

The case study is also implemented on HOMER software, for a time period of 8760 hours with system lifetime set at 25 years. An optimal configuration of $\mathrm{N}_{\mathrm{PV}}=57$ and $\mathrm{N}_{\mathrm{bat}}=21$ for an LPSP of $1.62 \%$ is obtained. These results are compared with the optimized results of ESCA methodology and presented in Table 5. 
Table 5 Comparison of results obtained from ESCA and HOMER

\begin{tabular}{|l|c|c|c|c|}
\hline Factor & ESCA (T = 8760 hrs) & HOMER & Variation w.r.t ESCA (\%) \\
\hline $\mathrm{N}_{\mathrm{PV}} / \mathrm{N}_{\text {bat }}$ & $42 / 14$ & $55 / 20$ & $57 / 21$ & - \\
\hline PV initial cost (\$) & 14112 & 17152 & 17776 & -3.63 \\
\hline Battery initial cost (\$) & 1820 & 2600 & 2730 & -5.00 \\
\hline Converter initial cost (\$) & 900 & 900 & 900 & 0.00 \\
\hline PV annualized cost (\$) & 1230 & 1611 & 1670 & -3.66 \\
\hline Battery annualized cost (\$) & 159 & 227 & 238 & -4.85 \\
\hline Converter annualized cost (\$) & 103 & 103 & 103 & 0.00 \\
\hline Initial cost (\$) & 16823 & 21980 & 22782 & -3.65 \\
\hline Net present cost (\$) & 23054 & 29248 & 30043 & -2.72 \\
\hline LCE (\$/kWh) & 0.1660 & 0.2160 & 0.2238 & -3.61 \\
\hline Epv (kWh/yr.) & 13822 & 18101 & 18759 & -3.64 \\
\hline Battery energy in (kWh/yr.) & 5965 & 8305 & 8707 & -4.84 \\
\hline Battery energy out (kWh/yr.) & 5569 & 5788 & 5786 & 0.03 \\
\hline Excess energy (kWh/yr.) & 396 & 2517 & 2921 & -16.05 \\
\hline LPSP (\%) & 6.59 & 1.85 & 1.62 & 12.43 \\
\hline Unmet load (kWh/yr.) & 1456 & 166 & 146 & 12.43 \\
\hline
\end{tabular}

As seen from the optimized results obtained, both the methods satisfy the predefined LPSP constraint with values of $1.85 \%$ and $1.62 \%$ for ESCA and HOMER respectively. Optimized configuration obtained from ESCA is two PV panels and one battery less in comparison to the result obtained from HOMER. Thereby making the system obtained from ESCA cheaper in comparison to that obtained from HOMER. The net present cost for system configuration obtained from ESCA is \$29248 and that of HOMER is \$30043 which is 2.72\% less. The levelized cost of energy obtained from ESCA is $0.2160 \$ / \mathrm{kWh}$ and from HOMER is 0.2238 \$/kWh which is $3.61 \%$ less. The total energy generated by the PV system is $18101 \mathrm{kWh}$ from ESCA and $18759 \mathrm{kWh}$ from HOMER, which is $3.64 \%$ less due to the larger rating of the system configuration thereby also making the annual unmet load $12.43 \%$ more in ESCA. Though there is minor difference in the results obtained from both the methods, ESCA due to its simplicity provides better insight into the designing and sizing of the HRES system.

\subsubsection{Comparison of proposed ESCA with other optimization methodology}

The merits of the ESCA methodology over other optimization methodologies are shown in Table 6. The improvements performed to the proposed by Ho et al. [23], [24] methodology are as follows:

i. $\quad$ More realistic results are obtained by performing analysis for time period of 288 hours and 8760 hours (1 year) considering monthly variations in load and climatic conditions.

ii. Variations in PV efficiency with temperature and BESS charging/discharging efficiency is considered, unlike Ho et al. [23], 24] which considers PV efficiency constant.

iii. Modelling of solar irradiance is also performed to achieve accurate solar radiation reaching the PV module which adds credibility to the obtained results.

iv. Multi-constraint optimization is performed with reliability constraints (FEE and LPSP) and economic constraints to obtain the final results which in case of Ho et al. [23], 24] was only performed formed for reliability. 
v. The system size is updated differently using (33), which guarantees the convergence of the optimization algorithm. In case of Ho et al. [23], [24], (32) is used for updating system size which may not converge if FEE is set to low or high.

Table 6 Improvements over other optimization methodologies

\begin{tabular}{|c|c|c|}
\hline Methodology & Demerits & ESCA Improvement \\
\hline \multirow[t]{5}{*}{ HOMER [50] } & $\begin{array}{l}\text { It only considers a single objective function to minimize } \\
\text { net present cost. }\end{array}$ & It considered both cost and reliability analysis. \\
\hline & HOMER does not consider DOD of BESS. & It is considered here. \\
\hline & It does not consider intra hour variability. & It is considered here. \\
\hline & The time step cannot be reduced below one hour. & $\begin{array}{l}\text { It can be considered less than one hour provided } \\
\text { data is available. }\end{array}$ \\
\hline & The code used for optimization is a "black box" & $\begin{array}{l}\text { The user can see and understand why and how a } \\
\text { particular result is obtained. }\end{array}$ \\
\hline \multirow[t]{3}{*}{ RETScreen [50] } & $\begin{array}{l}\text { Does not take into account the effect of PV output } \\
\text { variation with temperature. }\end{array}$ & It is considered here. \\
\hline & Time series data cannot be extracted. & It can be extracted. \\
\hline & Limited option of visualization of obtained data. & $\begin{array}{l}\text { The optimized data can be easily represented in } \\
\text { graphs and table. }\end{array}$ \\
\hline iHOGA [50] & $\begin{array}{l}\text { Can simulate system with maximum daily average load } \\
\text { of } 10 \mathrm{kWh}\end{array}$ & No restriction is imposed here. \\
\hline Software (generalized) & $\begin{array}{l}\text { The optimized result obtained is restricted to the } \\
\text { predefined user input, the most optimal solution may lie } \\
\text { outside the predefined range. }\end{array}$ & $\begin{array}{l}\text { The universal optimal solution is obtained } \\
\text { irrespective of the initial assumption made. }\end{array}$ \\
\hline Genetic algorithm [51] & $\begin{array}{l}\text { No guarantee to find best solution and it might be } \\
\text { difficult to obtain the global optimum solution. }\end{array}$ & $\begin{array}{l}\text { Optimal solution is independent of the initial } \\
\text { assumption and the convergence of ESCA is } \\
\text { improved in the proposed method. }\end{array}$ \\
\hline \multirow[t]{2}{*}{ Fuzzy logics [52] } & Difficult to formulate membership function. & No such difficulty here. \\
\hline & $\begin{array}{l}\text { System modelling is difficult, as analogues system needs } \\
\text { to be created. }\end{array}$ & $\begin{array}{l}\text { Inherently built for renewable energy system, so no } \\
\text { analogues comparison required. }\end{array}$ \\
\hline Neural network [51] & $\begin{array}{l}\text { Needs high processing time for training and system } \\
\text { modelling and training is complex for larger system. }\end{array}$ & $\begin{array}{l}\text { Processing power required is less and is } \\
\text { independent of the system component modelling. }\end{array}$ \\
\hline
\end{tabular}

\section{Conclusion}

This paper discusses the implementation of the improved ESCA methodology for optimization of a PV-BESS system based on the historical data, final excess energy, loss of system probability and economic constraints. The ESCA methodology is improved by incorporation of variation of PV and charge/discharge efficiency of the battery, consideration of attenuation in solar radiation reaching the PV collector surface and implementation of the method for a more realistic time period of a year. The ESCA methodology is implemented initially for time period of 288 hours and then for 8760 hours to improve upon the optimized results obtained from the first algorithm. It also shows that the time period of analysis greatly affects the optimum size of the system. The results thus obtained are compared and validated from HOMER software. There are certain improvements which can be incorporated into ESCA like, considering multi generation system, on/off grid mode of operation, addition of other reliability and optimization constraint, addition of parameters to make the system component modelling more realistic. These improvements will be communicated in future research work.

\section{References}

[1] K. K. Iychettira, R. A. Hakvoort, P. Linares, and R. de Jeu, "Towards a comprehensive policy for electricity from renewable energy: Designing for social welfare,” Appl. Energy, vol. 187, pp. 228-242, Feb. 2017.

[2] X. Liu, S. Zhang, and J. Bae, “The nexus of renewable energy-agriculture-environment in BRICS,” Appl. Energy, vol. 204, pp. 489496, Oct. 2017.

[3] Energy Information Administration (US), International Energy Outlook 2013 with Projections to 2040. Government Printing Office, 2013. 
[4] Y. Liu, S. Yu, Y. Zhu, D. Wang, and J. Liu, "Modeling, planning, application and management of energy systems for isolated areas: A review,” Renew. Sustain. Energy Rev., vol. 82, pp. 460-470, Feb. 2018.

[5] S. Yilmaz and F. Dincer, "Optimal design of hybrid PV-Diesel-Battery systems for isolated lands: A case study for Kilis, Turkey," Renew. Sustain. Energy Rev., vol. 77, pp. 344-352, Sep. 2017.

[6] L. Fara and D. Craciunescu, "Output Analysis of Stand-alone PV Systems: Modeling, Simulation and Control,” Energy Procedia, vol. 112, pp. 595-605, Mar. 2017.

[7] Y. S. Mohammed, M. W. Mustafa, and N. Bashir, "Hybrid renewable energy systems for off-grid electric power: Review of substantial issues,” Renew. Sustain. Energy Rev., vol. 35, pp. 527-539, Jul. 2014.

[8] B. Bhandari, K.-T. Lee, G.-Y. Lee, Y.-M. Cho, and S.-H. Ahn, "Optimization of hybrid renewable energy power systems: A review," Int. J. Precis. Eng. Manuf.-Green Technol., vol. 2, no. 1, pp. 99-112, Jan. 2015.

[9] R. Singh and R. C. Bansal, "Review of HRESs based on storage options, system architecture and optimisation criteria and methodologies,” IET Renew. Power Gener., vol. 12, no. 7, pp. 747-760, May 2018.

[10] A. Sani Hassan, L. Cipcigan, and N. Jenkins, “Optimal battery storage operation for PV systems with tariff incentives,” Appl. Energy, vol. 203, pp. 422-441, Oct. 2017.

[11] B. Zakeri and S. Syri, "Electrical energy storage systems: A comparative life cycle cost analysis,” Renew. Sustain. Energy Rev., vol. 42, pp. 569-596, Feb. 2015.

[12] S. Upadhyay and M. P. Sharma, "Development of hybrid energy system with cycle charging strategy using particle swarm optimization for a remote area in India,” Renew. Energy, vol. 77, pp. 586-598, May 2015.

[13] A. Maleki and A. Askarzadeh, "Comparative study of artificial intelligence techniques for sizing of a hydrogen-based stand-alone photovoltaic/wind hybrid system,” Int. J. Hydrog. Energy, vol. 39, no. 19, pp. 9973-9984, Jun. 2014.

[14] Y. A. Katsigiannis, P. S. Georgilakis, and E. S. Karapidakis, "Hybrid simulated annealing -tabu search method for optimal sizing of autonomous power systems with renewables,” IEEE Trans. Sustain. Energy, vol. 3, no. 3, pp. 330-338, Jul. 2012.

[15] P. Paliwal, N. P. Patidar, and R. K. Nema, "Determination of reliability constrained optimal resource mix for an autonomous hybrid power system using Particle Swarm Optimization,” Renew. Energy, vol. 63, pp. 194-204, Mar. 2014.

[16] E. Koutroulis and D. Kolokotsa, "Design optimization of desalination systems power-supplied by PV and W/G energy sources," Desalination, vol. 258, no. 1-3, pp. 171-181, Aug. 2010.

[17] S. Bahramara, M. P. Moghaddam, and M. R. Haghifam, "Optimal planning of hybrid renewable energy systems using HOMER: A review,” Renew. Sustain. Energy Rev., vol. 62, pp. 609-620, Sep. 2016.

[18] T. Hove and H. Tazvinga, "A techno-economic model for optimising component sizing and energy dispatch strategy for PV-dieselbattery hybrid power systems,” J. Energy South. Afr., vol. 23, no. 4, pp. 18-28, 2012.

[19] R. Singh, S. Awasthi, and G. Khanduri, "A case study on economic viability of a stand-alone and grid connected generation system for Mumbai,” in International Conference on Industrial Electronics and Electrical Engineering, Banglore, 2016, vol. 4, pp. 14-19.

[20] J. J. Klemeš and Z. Kravanja, "Forty years of Heat Integration: Pinch Analysis (PA) and Mathematical Programming (MP),” Curr. Opin. Chem. Eng., vol. 2, no. 4, pp. 461-474, Nov. 2013.

[21] S. R. Wan Alwi, N. E. Mohammad Rozali, Z. Abdul-Manan, and J. J. Klemeš, “A process integration targeting method for hybrid power systems," Energy, vol. 44, no. 1, pp. 6-10, Aug. 2012.

[22] S. Bandyopadhyay, "Design and optimization of isolated energy systems through pinch analysis," Asia-Pac. J. Chem. Eng., vol. 6, no. 3, pp. 518-526, May 2011.

[23] W. S. Ho, H. Hashim, M. H. Hassim, Z. A. Muis, and N. L. M. Shamsuddin, "Design of distributed energy system through Electric System Cascade Analysis (ESCA),” Appl. Energy, vol. 99, pp. 309-315, Nov. 2012.

[24] W. S. Ho, M. Z. W. M. Tohid, H. Hashim, and Z. A. Muis, "Electric System Cascade Analysis (ESCA): solar PV system,” Int. J. Electr. Power Energy Syst., vol. 54, pp. 481-486, Jan. 2014.

[25] R. C. Bansal, Handbook of Distributed Generation: Electric Power Technologies, Economics and Environmental Impacts. Switzerland: Springer, 2017.

[26] N. Agarwal, A. Kumar, and Varun, "Optimization of grid independent hybrid PV-diesel-battery system for power generation in remote villages of Uttar Pradesh, India,” Energy Sustain. Dev., vol. 17, no. 3, pp. 210-219, Jun. 2013.

[27] Y. Kalinci, A. Hepbasli, and I. Dincer, "Techno-economic analysis of a stand-alone hybrid renewable energy system with hydrogen production and storage options,” Int. J. Hydrog. Energy, vol. 40, no. 24, pp. 7652-7664, Jun. 2015.

[28] M. N. Kabir, Y. Mishra, and R. C. Bansal, "Coordinated operation of PV and battery energy storage systems," in Handbook of Clean Energy Systems, Sussex, UK: John Wiley \& Sons, Ltd, 2015.

[29] S. M. Lukic, J. Cao, R. C. Bansal, F. Rodriguez, and A. Emadi, “Energy Storage Systems for Automotive Applications,” IEEE Trans. Ind. Electron., vol. 55, no. 6, pp. 2258-2267, Jun. 2008.

[30] R. Hosseinalizadeh, H. Shakouri G, M. S. Amalnick, and P. Taghipour, "Economic sizing of a hybrid (PV-WT-FC) renewable energy system (HRES) for stand-alone usages by an optimization-simulation model: Case study of Iran,” Renew. Sustain. Energy Rev., vol. 54, pp. 139-150, Feb. 2016.

[31] S. Dubey and A. A. O. Tay, "Testing of two different types of photovoltaic-thermal (PVT) modules with heat flow pattern under tropical climatic conditions," Energy Sustain. Dev., vol. 17, no. 1, pp. 1-12, Feb. 2013.

[32] G. M. Masters, Renewable and Efficient Electric Power Systems. New Jersey, USA: John Wiley \& Sons, 2013.

[33] M. Collares-Pereira and A. Rabl, "The average distribution of solar radiation-correlations between diffuse and hemispherical and between daily and hourly insolation values,” Sol. Energy, vol. 22, no. 2, pp. 155-164, 1979.

[34] K. Li and K. J. Tseng, "Energy efficiency of lithium-ion battery used as energy storage devices in micro-grid,” in IECON 2015 - 41st Annual Conference of the IEEE Industrial Electronics Society, 2015, pp. 005235-005240.

[35] "A general battery model for PV system simulation - Copetti - 1993 - Progress in Photovoltaics: Research and Applications - Wiley Online Library.” [Online]. Available: http://onlinelibrary.wiley.com/doi/10.1002/pip.4670010405/full. [Accessed: 03-Oct-2017].

[36] Y. Zheng, M. Ouyang, L. Lu, J. Li, Z. Zhang, and X. Li, "Study on the correlation between state of charge and coulombic efficiency for commercial lithium ion batteries,” J. Power Sources, vol. 289, pp. 81-90, Sep. 2015.

[37] J. Kang, F. Yan, P. Zhang, and C. Du, “A novel way to calculate energy efficiency for rechargeable batteries,” J. Power Sources, vol. 206, pp. 310-314, May 2012.

[38] “Literature | Trojan Battery Company.” [Online]. Available: http://www.trojanbattery.com/literature/\#datasheets. [Accessed: 03-Oct2017].

[39] M. K. Deshmukh and S. S. Deshmukh, "Modeling of hybrid renewable energy systems," Renew. Sustain. Energy Rev., vol. 12, no. 1, pp. 235-249, Jan. 2008.

[40] A. H. Fathima and K. Palanisamy, “Optimization in microgrids with hybrid energy systems - A review," Renew. Sustain. Energy Rev., vol. 45, pp. 431-446, May 2015. 
[41] I. Baniasad Askari, M. Oukati Sadegh, and M. Ameri, "Energy management and economics of a trigeneration system Considering the effect of solar PV, solar collector and fuel price,” Energy Sustain. Dev., vol. 26, pp. 43-55, Jun. 2015.

[42] S. G. Sigarchian, A. Malmquist, and T. Fransson, "Modeling and control strategy of a hybrid PV/Wind/engine/battery system to provide electricity and drinkable water for remote applications,” Energy Procedia, vol. 57, pp. 1401-1410, Jan. 2014.

[43] L. K. Gan, J. K. H. Shek, and M. A. Mueller, "Hybrid wind-photovoltaic-diesel-battery system sizing tool development using empirical approach, life-cycle cost and performance analysis: A case study in Scotland,” Energy Convers. Manag., vol. 106, pp. 479494, Dec. 2015.

[44] S. Mahapatra and S. Dasappa, "Rural electrification: Optimising the choice between decentralised renewable energy sources and grid extension,” Energy Sustain. Dev., vol. 16, no. 2, pp. 146-154, Jun. 2012.

[45] B. S. Borowy and Z. M. Salameh, "Methodology for optimally sizing the combination of a battery bank and PV array in a wind/PV hybrid system,” IEEE Trans. Energy Convers., vol. 11, no. 2, pp. 367-375, Jun. 1996.

[46] R. Siddaiah and R. P. Saini, "A review on planning, configurations, modeling and optimization techniques of hybrid renewable energy systems for off grid applications,” Renew. Sustain. Energy Rev., vol. 58, pp. 376-396, May 2016.

[47] H. Zahboune, S. Zouggar, M. Elhafyani, M. Ziani, and S. Dahbi, "Optimal design method for stand-alone solar system with LPSP technology by using electric system cascade analysis method,” in 3rd International Renewable and Sustainable Energy Conference (IRSEC), Morocco, 2015, pp. 1-6.

[48] “Commercial and Residential Hourly Load Profiles for all TMY3 Locations in the United States - OpenEI DOE Open Data.” [Online]. Available: https://openei.org/doe-opendata/dataset/commercial-and-residential-hourly-load-profiles-for-all-tmy3-locations-in-theunited-states. [Accessed: 03-Oct-2017].

[49] G. Halász and Y. Malachi, "Solar energy from Negev desert, Israel: Assessment of power fluctuations for future PV fleet,” Energy Sustain. Dev., vol. 21, pp. 20-29, Aug. 2014.

[50] S. Sinha and S. S. Chandel, "Review of software tools for hybrid renewable energy systems," Renew. Sustain. Energy Rev., vol. 32, pp. 192-205, Apr. 2014.

[51] A. Ansari and A. A. Bakar, "A Comparative Study of Three Artificial Intelligence Techniques: Genetic Algorithm, Neural Network, and Fuzzy Logic, on Scheduling Problem,” 2014, pp. 31-36.

[52] J. V. Tu, “Advantages and disadvantages of using artificial neural networks versus logistic regression for predicting medical outcomes,” J. Clin. Epidemiol., vol. 49, no. 11, pp. 1225-1231, Nov. 1996. 